\title{
Isolation and characterization of HepP: a virulence-related Pseudomonas aeruginosa heparinase
}

\author{
Nyaradzo Dzvova', Jane A. Colmer-Hamood ${ }^{1,2}$, John A. Griswold ${ }^{3}$ and Abdul N. Hamood ${ }^{1,3^{*}}$ (D
}

\begin{abstract}
Background: Pseudomonas aeruginosa is an opportunistic pathogen that causes serious infections in immunocompromised hosts including severely burned patients. In burn patients, P. aeruginosa infection often leads to septic shock and death. Despite numerous studies, the influence of severe thermal injuries on the pathogenesis of $P$. aeruginosa during systemic infection is not known. Through RNA-seq analysis, we recently showed that the growth of $P$. aeruginosa strain UCBPPPA14 (PA14) in whole blood obtained from severely burned patients significantly altered the expression of the PA14 transcriptome when compared with its growth in blood from healthy volunteers. The expression of PA14_23430 and the adjacent gene, PA14_23420, was enhanced by seven- to eightfold under these conditions.

Results: Quantitative real-time PCR analysis confirmed the enhancement of expression of both PA14_23420 and PA14_23430 by growth of PA14 in blood from severely burned patients. Computer analysis revealed that PA14_23430 (hepP) encodes a potential heparinase while PA14_23420 (zbdP) codes for a putative zinc-binding dehydrogenase. This analysis further suggested that the two genes form an operon with zbdP first. Presence of the operon was confirmed by RT-PCR experiments. We characterized hepP and its protein product HepP. hepP was cloned from PA14 by PCR and overexpressed in E. coli. The recombinant protein (rHepP) was purified using nickel column chromatography. Heparinase assays using commercially available heparinase as a positive control, revealed that $\mathrm{rHepP}$ exhibits heparinase activity. Mutation of hepP resulted in delay of pellicle formation at the air-liquid interface by PA14 under static growth conditions. Biofilm formation by PA14 $\Delta$ hepP was also significantly reduced. In the Caenorhabditis elegans model of slow killing, mutation of hepP resulted in a significantly lower rate of killing than that of the parent strain PA14.

Conclusions: Changes within the blood of severely burned patients significantly induced expression of hepP in PA14. The heparinase encoded by hepP is a potential virulence factor for PA14 as HepP influences pellicle formation as well as biofilm development by PA14 and the protein is required for full virulence in the C. elegans model of slow killing.
\end{abstract}

Keywords: Pseudomonas aeruginosa, Heparinase, Virulence, Pellicle, Biofilm, C. elegans killing model

\section{Background}

The gram-negative opportunistic pathogen Pseudomonas aeruginosa causes severe infection in immunocompromised hosts such as HIV-infected patients, individuals with cystic fibrosis, cancer patients, transplant patients, and severely burned patients $[1,2]$. Damage caused during different $P$.

\footnotetext{
* Correspondence: abdul.hamood@ttuhsc.edu

'Department of Immunology and Molecular Microbiology, Texas Tech University Health Sciences Center, 3601 4th St. Mail Stop 6591, Lubbock, TX 79430, USA

${ }^{3}$ Department of Surgery, Texas Tech University Health Sciences Center, Lubbock, TX, USA

Full list of author information is available at the end of the article
}

aeruginosa infections is due to the production of numerous cell-associated and extracellular virulence factors [2-5]. The extracellular factors include proteases such as elastase, hemolysins such as phospholipase $\mathrm{C}$, siderophores such as pyoverdine, and toxins such as exotoxin A. The cellassociated virulence factors include flagellum, alginate and pili [6, 7].

A severe burn destroys the skin barrier and reduces the expression of both local and systemic immune responses [8-11]. Additionally, substances that are produced by the injured cells within the burned wound impair local host immune responses $[8,11,12]$. Although burn wounds are initially sterile they are quickly colonized by bacterial 
pathogens including $P$. aeruginosa $[13,14]$. $P$. aeruginosa grows within the wound and translocates to the blood stream causing bacteremia which is followed by sepsis, septic shock and multiorgan failure. Despite numerous studies, the influence of severe burn injury on the pathogenesis of $P$. aeruginosa during systemic infection is not completely understood. We recently followed a unique approach to address this issue. Instead of growing P. aeruginosa in a regular laboratory medium, we grew it in whole blood from either healthy volunteers or severely burned patients and conducted a comparative transcriptome analysis [15]. RNA-seq analysis showed that the growth of $P$. aeruginosa strain UCBPP-PA14 (PA14) in whole blood obtained from severely burned patients significantly altered the expression of the PA14 transcriptome when compared with its growth in blood from healthy volunteers [15]. Among genes not reported in the previous study whose expression was enhanced were PA14_23430, which codes for a putative heparinase, and the adjacent gene PA14_23420.

Heparin and heparan sulfate glycosaminoglycans (HSGAGs), which consist of linear chains of disaccharide units of $N$-acetylated D-glucosamine $\alpha(1-4)$ linked to glucuronic acids, are present on the surface of different mammalian cells and the extracellular matrices [16]. Enzymes that degrade HSGAGs by specifically cleaving the 1-4 glycosidic link in heparin and heparan sulfate are known as heparanase or heparinase [16]. Mammalian heparanases cleave at the reducing end of glucuronic acid by a hydrolytic mechanism whereas bacterial heparinases depolymerize heparin and heparan sulfate by $\beta$-elimination cleavage $[16,17]$. Heparanases, which are important modulators of the extracellular matrices, are present in normal cells including endothelial cells, cytotrophoblasts, platelets, mast cells, neutrophils, macrophages, and lymphocytes [16, 18-21]. Heparanase expression is increased in certain human carcinomas and hematological malignancies [20, 21]. Heparanases also function in nontumorous processes including, tissue morphogenesis, regeneration and repair during embryonic development and wound repair [20-23].

The best-characterized bacterial heparinases are the three enzymes produced by Pedobacter heparinus, (previously known as Flavobacterium heparinum) heparinase I, II, and III [16, 17, 22, 24-27]. No significant homology exists between either the DNA sequences of the genes that code for the three heparinases or the amino acid sequences of the proteins [28]. The three heparinases proved to be valuable tools in analyzing different structural, biochemical and physiological properties of heparin and heparan sulfate-like glycosaminoglycans $[18,22,24,26]$. Additional uses of $P$. heparinus heparinases include heparinase I as a heparin antagonist [16, 29] and heparinases I, II, and III to reduce neovascularization during tumor progression through their ability to alter the action of fibroblast growth factor [16, 20, $21,27]$. Despite the proposed beneficial effects of the $P$. heparinus heparinases, it is not known if heparinases play a role in the pathogenesis of bacterial pathogens, specifically the ones that cause systemic infection.

In this study, we report the characterization of PA14_23430, or hepP, and its protein product HepP. hepP was cloned from PA14 by PCR and overexpressed in $E$. coli. The recombinant protein (rHepP) was purified using nickel column chromatography. The heparinase assay using commercially available heparinase revealed that rHepP exhibits heparinase activity. The deletion of hepP resulted in the delay of pellicle formation at the air-liquid interface by PA14 under static growth conditions. The biofilm formation by PA14 4 epP was also significantly reduced. In the Caenorhabditis elegans model of slow killing, the deletion of hepP resulted in a significantly lower rate of killing than that of the parent strain PA14.

To our knowledge this is the first time a heparinase, or heparin and heparin sulfate degrading enzyme, has been characterized from $P$. aeruginosa. Due to its important role in PA14 virulence and as $P$. aeruginosa antibiotic resistant mutants emerge at an alarming rate, HepP represent a potential target for new antimicrobial agents.

\section{Methods}

\section{Strains, plasmids and general growth conditions}

Bacterial strains and plasmids used in this study are listed in Table 1. The P. aeruginosa strain UCBPP_PA14 (PA14), originally isolated from an infected wound, or its specific transposon mutants, PA14 $4 h e p P$ and PA14 $\Delta z b d P$, were used in all the experiments [30,31]. The strains were routinely grown at $37^{\circ} \mathrm{C}$ in Luria Bertani (LB) broth. Gentamicin was added to the growth medium at a concentration of 60 $\mu \mathrm{g} / \mathrm{mL}$ for the PA14 mutants and carbenicillin was added at $100 \mu \mathrm{g} / \mathrm{mL}$ for $E$. coli strains carrying plasmids.

\section{Real time quantitative PCR (qPCR) and reverse transcription PCR (RT-PCR)}

Purified RNA samples obtained during a previous study in which we examined changes in the transcriptome of PA14 when grown in whole blood from severely burned patients compared with its growth in whole blood from healthy volunteers [15] were used in this study. The blood samples were obtained under an IRB-approved protocol in compliance with ethical practices [15].

Additional RNA samples were collected to examine the effect of the hepP mutation on the expression of specific virulence factors. We grew the strains in specific media, LB broth for the expression of quorum sensing genes and calcium-deficient chelexed trypticase soy broth dialysate medium for the expression of the type three secretion system (T3SS) genes [32], that are designed to maximally express those virulence genes. Briefly, PA14 cultures were 
Table 1 Strains and plasmids used in this study

\begin{tabular}{|c|c|c|}
\hline $\begin{array}{l}\text { Strains or } \\
\text { plasmids }\end{array}$ & Characteristics & Reference \\
\hline \multicolumn{3}{|c|}{ Pseudomonas aeruginosa } \\
\hline PA14 & $\begin{array}{l}\text { UCBPP-PA14; prototropic strain isolated } \\
\text { from infected wound }\end{array}$ & {$[30,31]$} \\
\hline PA14 $\triangle$ hepP & PA14/MrT7::PA14_23430-480; $\mathrm{Gm}^{\mathrm{R}}$ & {$[30]$} \\
\hline $\mathrm{PA} 14 \Delta z b d P$ & PA14/MrT7::PA14_23420-118; Gm ${ }^{R}$ & {$[30]$} \\
\hline \multicolumn{3}{|c|}{ Escherichia coli } \\
\hline TOP10 & $\begin{array}{l}\text { F- mcrA } \Delta(\text { mrr-hsdRMS-mcrBC) } \\
\text { Ф80lacZ } \Delta \text { M15 } \Delta \text { lacX74 recA1 araD139 } \\
\Delta\left(\text { ara-leu)7697 galU galK rpsL (Str }{ }^{R}\right) \\
\text { endA1 nupG }\end{array}$ & Invitrogen \\
\hline OP50 & $\begin{array}{l}\text { Uracil auxotroph; feeder strain for } \\
\text { Caenorhabditis elegans }\end{array}$ & [49] \\
\hline \multicolumn{3}{|c|}{ Caenorhabditis elegans } \\
\hline BW54 & $\begin{array}{l}\text { Temperature sensitive embryonic } \\
\text { lethal strain; proliferates at } 15^{\circ} \mathrm{C} ; \\
\text { sterile at } 25^{\circ} \mathrm{C}\end{array}$ & $\begin{array}{l}\text { Caenorhabditis } \\
\text { Genetics Center }\end{array}$ \\
\hline \multicolumn{3}{|l|}{ Plasmids } \\
\hline $\begin{array}{l}\text { pBAD/ } \\
\text { Thio-TOPO }\end{array}$ & $\begin{array}{l}\text { pBR322-derived expression vector; } \\
\text { cloned genes expressed from } \mathrm{P}_{\mathrm{BAD}} \\
\text { amino terminus HP-thioredoxin; carboxy } \\
\text { terminus } \mathrm{V} 5 \text { epitope and } 6 \mathrm{XHis} \text {; } \mathrm{Cb}^{\mathrm{R}}\end{array}$ & Invitrogen \\
\hline pND1 & pBAD/Thio-TOPO/hepP; $\mathrm{Cb}^{\mathrm{R}}$ & This study \\
\hline
\end{tabular}

$\mathrm{Cb}^{R}$ carbenicillin resistant, $\mathrm{Gm}^{R}$ gentamincin resistant, $\mathrm{Str}^{R}$

streptomycin resistant

grown and subcultured as described above. At the $8 \mathrm{~h}$ time point, cultures grown in the specific medium were mixed with twice the volume of the culture of RNAprotect Bacteria Reagent (Qiagen). After a $5 \mathrm{~min}$ incubation at room temperature, the cells were pelleted and stored at $-80{ }^{\circ} \mathrm{C}$. RNA was extracted using the RNeasy Mini Kit (Qiagen) according to the manufacturer's recommendations. To ensure purity, the RNA solution was digested with the RNase-free DNase set (Qiagen), the RNA was purified from the DNase by the RNA cleanup protocol (Qiagen), and quantified using a NanoDrop Spectrophotometer (NanoDrop Technologies).

Samples with an $A_{260 / 280}$ ratio of $1.8-2.2$ were used to synthesize cDNA by means of the QuantiTect Reverse Transcription kit (Qiagen). Two hundred ng of cDNA was mixed with PowerSYBR Green Master mix (Applied Biosystems) and $250 \mathrm{nM}$ of specific primer (Table 2). The StepOnePlus Real-Time PCR System (Applied Biosystems) was then used to detect and quantify amplification of the PCR product. Three independent replicates for RNA samples were used for each experiment; additionally, each qPCR reaction was set up in triplicate. Normalization of the cDNA quantity in the different experiments was done using the $30 \mathrm{~S}$ ribosomal subunit RNA (rpsL) as an internal standard. The software StepOnePlus version 2.2.2 was used to analyze gene expression. Negative control samples containing RNA as a template and positive control samples
Table 2 Primers used in this study

\begin{tabular}{|c|c|c|}
\hline Name & Sequence & Use \\
\hline hepP-For1 & GGACTGGCAAGCTGATAGGA & $\begin{array}{l}\text { Analysis of hepP } \\
\text { transcription } \\
\text { Analysis of operon }\end{array}$ \\
\hline hepP-Rev1 & CGATACGCAAGGAAAGAGGA & $\begin{array}{l}\text { Analysis of hepP } \\
\text { transcription } \\
\text { Analysis of operon }\end{array}$ \\
\hline zbdP-For1 & CGGGTGTTGGCTATTGATTT & $\begin{array}{l}\text { Analysis of } z b d P \\
\text { transcription }\end{array}$ \\
\hline zbdP-Rev1 & AACAATCCGTCCACGCTTAC & $\begin{array}{l}\text { Analysis of } z b d P \\
\text { transcription }\end{array}$ \\
\hline zbdP-For2 & CTTCTGAGGACAAGGCTTCG & Analysis of operon \\
\hline hepP-Rev2 & GATAAGGCTCCCAACCTTC & Analysis of operon \\
\hline zbdP-For3 & AGCCGACTATCGCTTGTGAA & $\begin{array}{l}\text { Confirmation of hepP } \\
\text { mutation }\end{array}$ \\
\hline hepP-Rev3 & GTGCTITTCGAGCAATGGAG & $\begin{array}{l}\text { Confirmation of hepP } \\
\text { mutation }\end{array}$ \\
\hline hepP-ATG & ATGGCACTTCAAAAACTCGTCCG & Cloning hepP \\
\hline hepP-[-TGA] & ACTCGTATTTGCTGGGGTGGAATT & Cloning hepP \\
\hline Trx Forward & TTCCTCGACGCTAACCTG & $\begin{array}{l}\text { Confirmation of } \\
\text { cloning }\end{array}$ \\
\hline pBAD Reverse & GATTAATCTGTATCAGG & $\begin{array}{l}\text { Confirmation of } \\
\text { cloning }\end{array}$ \\
\hline hepP-For2 & CGCTGGTGCAACAAGTAGAA & $\begin{array}{l}\text { Analysis of hepP } \\
\text { transcription }\end{array}$ \\
\hline hepP-Rev4 & GCGTGATACATCGGAGACAA & $\begin{array}{l}\text { Analysis of hepP } \\
\text { transcription }\end{array}$ \\
\hline
\end{tabular}

Primers were purchased from Integrated DNA Technologies

containing genomic DNA as a template were included for each experiment. RT-PCR was done as above but the CDNA products were analyzed on agarose gels. Primers used for all experiments involving PCR, RT-PCR or qPCR were synthesized by Integrated DNA Technologies and are listed in Table 2 and (Additional file 1: Table S1).

\section{Cloning of hepP}

The DNA sequence of hepP was amplified with GoTaq Green Master Mix (Promega) using primers described in Table 2 and genomic DNA from strain PA14 as a template. The 1650-bp amplicon was cloned into pBAD/Thio-TOPO (Invitrogen) to create plasmid pND1. The construction of pND1 was confirmed by restriction enzyme digestion and sequencing analysis. Recombinant HepP (rHepP) expressed from pND1 has the HP-thioredoxin fusion for efficient translation at the N-terminus and a $6 \mathrm{xHis}$ fusion for purification at the C-terminus plus the V5 epitope for localization of the protein by Western blotting.

Expression and purification of recombinant HepP (rHepP) Plasmid pND1 was transformed into chemically competent OneShot TOP10 Escherichia coli (Invitrogen). TOP10/ pND1 was grown in $50 \mathrm{~mL} \mathrm{LB}$ broth at $37^{\circ} \mathrm{C}$ with shaking, expression of hepP was induced with $0.02 \%$ L-arabinose, 
and the cultures incubated for an additional $4 \mathrm{~h}$. To avoid denaturation of the protein during purification, rHepP was purified under native conditions using a nickel-nitrilotriacetic acid affinity column (Ni-NTA, Qiagen) according to the manufacturer's protocol. Briefly, following induction, the cells were centrifuged and the pellet was suspended in lysis buffer (50 mM NaH $\mathrm{PO}_{4}, 300 \mathrm{mM} \mathrm{NaCl}, 10 \mathrm{mM}$ imidazole at $\mathrm{pH}$ 8). The cell suspension was sonicated for 10 cycles of a $10 \mathrm{~s}$ burst with a $10 \mathrm{~s}$ cooling between bursts. Lysed cells were centrifuged at $10,000 \times g$ for $20 \mathrm{~min}$. The supernatant was applied to a column containing 50\% Ni-NTA agarose slurry. The column was capped and the mixture was rotated for $60 \mathrm{~min}$ at $4{ }^{\circ} \mathrm{C}$. The column was then uncapped and the flow-through was collected. The column was washed twice with wash buffer $\left(50 \mathrm{mM} \mathrm{NaH}_{2} \mathrm{PO}_{4}, 300 \mathrm{mM} \mathrm{NaCl}, 20 \mathrm{mM}\right.$ imidazole at $\mathrm{pH} 8$ ) and rHepP was eluted with four applications of elution buffer $\left(50 \mathrm{mM} \mathrm{NaH} \mathrm{PO}_{4}, 300 \mathrm{mM} \mathrm{NaCl}\right.$, $250 \mathrm{mM}$ imidazole at $\mathrm{pH}$ 8). The concentration of the purified protein was estimated using the Bradford assay as previously described [33]. The purified protein was analyzed using $10 \%$ SDS-PAGE [34, 35]. In addition, we confirmed the production of the recombinant protein by immunoblotting experiments using anti-V5 antibody (Invitrogen).

\section{Heparinase activity plate assay}

The method is based on the ability of heparinase to cleave heparin and heparan sulfate [36]. Different concentrations of the samples to be tested were spotted on plates containing porcine intestinal heparin (1- $\mathrm{mg} / \mathrm{mL})$ (Sigma-Aldrich), $0.25 \mathrm{M}$ sodium acetate, and $0.0025 \mathrm{M}$ calcium acetate in $1.5 \%$ agarose at $\mathrm{pH} 7$. The plates were incubated for $1 \mathrm{~h}$ at $37^{\circ} \mathrm{C}$ and then $2 \%$ protamine sulfate solution (SigmaAldrich) was poured over the plates. The plates were incubated for $1-2 \mathrm{~h}$ at room temperature until a white precipitate formed on the uninoculated portions of the plate. The presence of clear zones indicate heparinase activity, with zones of increasing intensity at the areas where higher amounts of heparinase were added. Commercially available $P$. heparinus heparinase III $(0.5-1-\mathrm{U})$ (Sigma-Aldrich) was used as a positive control. The protein elution buffer was used as a negative control.

\section{Growth curve analysis}

The strains were grown overnight in LB broth and subcultured into fresh LB broth to a starting $\mathrm{OD}_{600}$ of 0.02 . Ten-mL aliquots of the inoculum were dispensed into 250-mL flasks, the cultures were grown with vigorous shaking at $37^{\circ} \mathrm{C}$ for $48 \mathrm{~h}$, and samples were obtained every $4 \mathrm{~h}$. To determine the number of viable bacterial cells at each time point, we serially diluted each sample (1:10) and $10-\mu \mathrm{L}$ aliquots were plated on LB agar plates. The plates were incubated at $37{ }^{\circ} \mathrm{C}$ overnight and the numbers of colonies produced from each dilution was counted (colony forming units [CFU]). The final CFU/
$\mathrm{mL}$ is obtained by the formula, $\mathrm{CFU} / \mathrm{mL}=$ (number of colonies $\mathrm{x}$ dilution factor)/sample volume. Each experiment was performed in three independent replicates.

\section{Analysis of virulence factors}

Different experiments were done to determine the effects of the mutation of hepP and $z b d P$ on the expression of virulence factors as previously described. For the analysis of elastase (LasB) activity, PA14 $\Delta h e p P$ and PA14 $\Delta z b d P$ were grown in LB broth at $37^{\circ} \mathrm{C}$; supernatants were collected at $14 \mathrm{~h}$ and used in the elastin Congo red tube assay [34, 37]. For pyoverdine production, the strains were grown in chelexed trypticase soy broth dialysate (TSB-DC) at $32{ }^{\circ} \mathrm{C}$ for $14 \mathrm{~h}$, the supernatants were collected, and pyoverdine levels were determined spectrophotometrically at $A_{405}$ [38]. The strains were grown in glycerol alanine medium at $37^{\circ} \mathrm{C}$ for $24 \mathrm{~h}$ for evaluation of pyocyanin production [39]. Pyocyanin was extracted from the supernatant fractions with chloroform and $0.2 \mathrm{M} \mathrm{HCl}[37,40]$. Assays for swimming (flagellar) and twitching (pilus-associated) motilities were done as previously described [41, 42]. Strains grown overnight on LB agar plates at $37^{\circ} \mathrm{C}$ were stabbed onto the surface of $1 \%$ tryptone/0.3\% agar $(w / v)$ plates (swimming motility) or to the bottom of $1 \%$ LB agar plates (twitching motility) and incubated for 16 or $24 \mathrm{~h}$, respectively; zones of motility were measured as described [37, 41, 42].

The analysis of the effect hepP and $z b d P$ mutations on the expression of quorum-sensing (QS) genes and T3SS genes was done by RT-qPCR. PA14 $\triangle h e p P$ and PA14 $\Delta z b d P$ were grown for $16 \mathrm{~h}$ in LB broth for QS genes and for $16 \mathrm{~h}$ in TSB-DC containing nitrilotriacetic acid for T3SS genes [37] and the cells were pelleted. The RNA was extracted, purified, reverse transcribed, and subjected to qPCR as described above in Methods using primers described in Additional file 1: Table S1.

\section{Formation of pellicle and biofilm}

The air-liquid interface (ALI) method of biofilm development was used to observe both pellicle formation and biofilm development [43-45]. The strains were grown overnight in LB broth and subcultured into fresh LB broth to a starting $\mathrm{OD}_{600}$ of $0.02[41,46,47]$. Three-mL aliquots of the inoculum were dispensed into $17 \mathrm{~mm} \times$ $100 \mathrm{~mm}$ polystyrene tubes and incubated at $37^{\circ} \mathrm{C}$ for 24 to $48 \mathrm{~h}$. For pellicle formation, the tubes were incubated under static conditions and observed at 24 and $48 \mathrm{~h}$ post inoculation for pellicle formation and the relative turbidity of the broth below the ALI (planktonic growth). For the analysis of biofilm formation, the tubes were grown with gentle shaking. At 24 or $48 \mathrm{~h}$ post inoculation, planktonic growth was removed, the adherent biofilms were washed with distilled water to remove any nonadherent cells, and stained with $1 \%$ crystal violet. The biofilms were then washed twice with distilled water, the 
crystal violet eluted from the biofilms with 95\% ethanol, and the color was measured spectrophotometrically at $A_{590}[41,46,47]$.

\section{Caenorhabditis elegans slow-killing assay}

This assay was performed as previously described [48]. The temperature-sensitive embryonic lethal C. elegans strain BW54 was obtained from the Caenorhabditis Genetics Center (https://cgc.umn.edu; accessed 12/12/ 2017) (Table 1) and maintained at $15{ }^{\circ} \mathrm{C}$ for proliferation or $25{ }^{\circ} \mathrm{C}$ for storage without proliferation. For the survival studies, $5-15 \mu \mathrm{L}$ of overnight cultures of the test strains, PA14 as a positive control, or E. coli OP50, a traditional feeder source, as the negative control, were spread on $3.5-\mathrm{cm}$ plates containing nematode growth agar and incubated at $37{ }^{\circ} \mathrm{C}$ for $24 \mathrm{~h}$ [49]. Each plate was then seeded with 10 nematodes and the plates were incubated at $25{ }^{\circ} \mathrm{C}$ to prevent proliferation of BW54. Plates were examined every day for 5 days under a dissecting microscope and the numbers of surviving worms recorded. A worm was considered dead when it stopped responding to touch. Each experiment was replicated three to six times.

\section{Statistical analysis}

Statistical analyses of the results were done using GraphPad Prism 7.0 (GraphPad Software).

\section{Results}

The expression of PA14_23420 and PA14_23430 is influenced by thermal injury-induced changes in blood We recently examined the effect of thermal injury-induced changes in blood on the expression of $P$. aeruginosa genes [15]. P. aeruginosa strain PA14 was grown in whole blood from either healthy volunteers (BHV) or severely burned (thermally-injured) patients (BTI) and the level of gene expression was examined by RNA-seq analysis [15]. Among the genes whose expression was significantly enhanced were the adjacent genes PA14_23420 and PA14_23430. PA14_23420 (zbdP) encodes a hypothetical zinc binding dehydrogenase, while PA14_23430 (hepP) codes for a hypothetical heparinase. Compared with BHV, the growth of PA14 in BTI enhanced the expression of $z b d P$ and hepP by approximately seven- to eight-fold in each of three male patients (Table 3). Despite differences in age (28-62 years), percentage of total body surface involved in the burn injury (25-50\%), and source of burn (fire or explosion) [15], the increase in gene expression was comparable among the three patients (Table 3 ). We confirmed these results by real time quantitative PCR analysis (qPCR) of the RNA samples obtained during the RNA-seq analysis. Compared with the growth in BHV, the growth of PA14 in BTI increased the expression of hepP and $z b d P$ by approximately five- and sixfold, respectively (Fig. 1).
Table 3 RNA-Seq expression of zbdP and hepP

\begin{tabular}{lllll}
\hline & & \multicolumn{2}{l}{$\begin{array}{l}\text { Fold change compared to healthy } \\
\text { volunteer }\end{array}$} \\
\cline { 3 - 5 } Gene & Protein Function ${ }^{\mathrm{a}}$ & Patient 1 & Patient 2 & Patient 3 \\
\hline zbdP & Zinc-binding dehydrogenase & 6.8 & 7.5 & 7.9 \\
hepP & Heparinase & 7.1 & 7.6 & 8.1 \\
\hline
\end{tabular}

${ }^{a}$ Protein functions were obtained from the Pseudomonas Genome Database (http://pseudomonas.com/; accessed 12/12/2017); [54]

${ }^{b}$ Expression of zbdP (PA14_23420) and hepP (PA14_23430) in PA14 that was grown in blood from three burn patients was compared with expression when PA14 was grown in blood from a healthy volunteer. Genes were identified as differentially expressed with $\geq$ two-fold change if they had the false discovery rate correction $p$-value of $\leq 0.01$ [15]

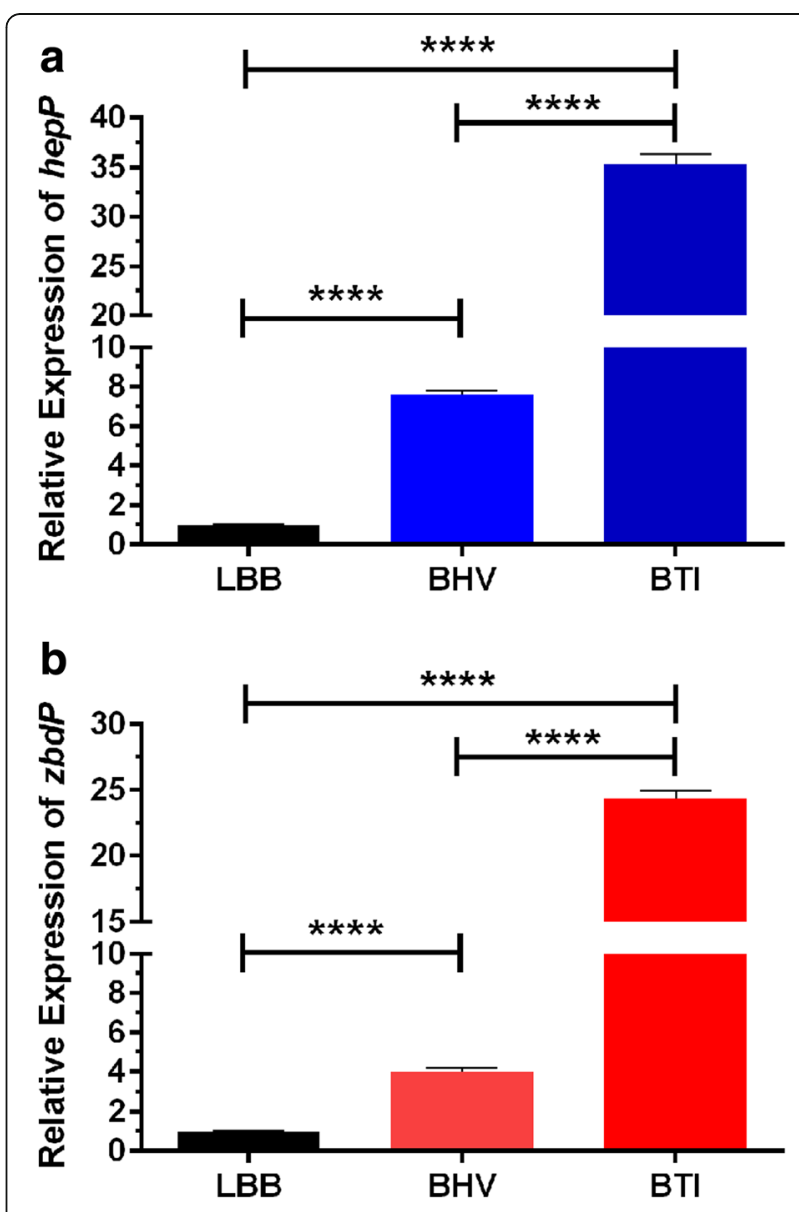

Fig. 1 Growth of PA14 in whole blood from a severely burned patient enhanced expression of hepP and zbdP. RNA samples obtained from PA14 that was grown for $8 \mathrm{~h}$ at $37^{\circ} \mathrm{C}$ in LB broth (LBB), whole blood from a healthy volunteer (BHV), or whole blood from a patient with severe thermal injury (BTI) were used in RT-qPCR reactions as described in Methods using primers listed in Table 2. a Expression of hepP; $\mathbf{b}$ expression of $z b d P$. Values in $\mathbf{a}$ and $\mathbf{b}$ represent the means of triplicate experiments conducted on three independently obtained samples \pm SEM. ${ }^{* * *}, P<0.0001$ 
In addition to the burn-induced effect, the growth of PA14 in BHV, compared with the growth in a regular laboratory medium such as LB broth, may influence the expression of either or both genes. To examine this possibility, we grew PA14 either in LB broth (LB) or in BHV and analyzed the expression of hepP and $z b d P$ by qPCR. The growth of PA14 in BHV enhanced expression of these genes by seven- and fourfold, respectively (Fig. 1). These results suggest that, with respect to the growth in whole blood, the increase in the expression of hepP and $z b d P$ occurs at two levels. First, there is a blood-related increase (BHV vs LB) that is likely to be triggered by certain components of whole blood; then there is a further increase (BHV vs BTI) that is likely to be triggered by thermal injury-induced changes in blood.

\section{hepP encodes a potential heparinase while $z b d P$ encodes a potential zinc-binding dehydrogenase}

Computer analysis of the $61.9-\mathrm{kDa}$ predicted protein encoded by hepP using the Conserved Domains database (https://www.ncbi.nlm.nih.gov/Structure/cdd/wrpsb.cgi; accessed 12/12/2017) revealed the presence of two specific domains within the amino and carboxy terminus regions [50]. The amino-terminus domain (amino acid [aa] 116 to aa 288) has the characteristics of the chondroitin AC/alginate lyase superfamily/heparinase_IIIII_N domain (Additional file 1: Figure S1a). A number of bacterial species including $P$. heparinus synthesize glycosaminoglyacans (GAGs) lyases, such as these chondroitin AC/alginate lyases, to degrade and utilize GAGs as a carbon source [24]. The carboxy terminus domain (aa 324 to aa 547) has the characteristics of the heparinase_II_III superfamily, specifically the $P$. heparinus heparinase II/III domain (Additional file 1: Figure S1a). A homology search using Protein BLAST (https://blast.ncbi.nlm.nih.gov/Blast.cgi; accessed 12/12/2017) and the nonredundant protein sequences database revealed that this domain in HepP is homologous to domains found in predicted proteins encoded by several other bacteria including Pseudomonas fluorescens, multiple Acinetobacter spp., Shigella boydii, Edwardsiella tarda, and Vibrio vulnificus (Additional file 1: Figure S1b) [51]. The strongest overall homology exists between the PA14 HepP and P. fluorescens F113 heparinase (Additional file 1: Figure S1b). Additional analysis for localization of HepP using the database PSORTb (http://www.psort.org/psortb/ ; version 3.0.2; accessed 12/12/2017) failed to detect a typical type 1 protein export signal or a cleavage site within the amino terminus of the predicted protein (data not shown) $[52,53]$. Thus, whether the HepP is extracellular or cytoplasmic is unknown.

A similar computer analysis conducted on the $78-\mathrm{kDa}$ predicted protein encoded by $z b d P$, revealed the presence of five conserved domains; two within the amino terminus regions and three within the carboxy terminus regions (Additional file 1: Figure S2). The amino-terminus domains are the 2-deacetyl-2-hydroxyethyl bacteriochlorophyllidelike medium chain dehydrogenase reductase (MDR) (aa 81 to aa 373) which is overlapped by the threonine dehydrogenase or related zinc-dependent dehydrogenase (Tdh) domain (aa 9 to aa 373). Additionally, the conserved putative $\mathrm{NAD}(\mathrm{P})$ binding sites found in MDR/Tdh proteins were also detected. The three conserved $\mathrm{C}$-terminus domains include the NADB_Rossmann domain (aa 402 to aa 524), the oxidoreductase Gfo/Idh/MocA domain (aa 562 to aa 645), and the MviM or predicted dehydrogenase family domain (aa 402 to aa 714) which includes both of the other $\mathrm{C}$-terminus domains.

Computer analysis using the Pseudomonas Genomic Database [54] revealed that $z b d P$ is located immediately upstream of hepP with the two genes separated by eight bp (Additional file 1: Figure S3), which suggests the two genes constitute an operon. To confirm this, RNA was extracted from PA14 grown in LB broth at $37{ }^{\circ} \mathrm{C}$ for $8 \mathrm{~h}$ and used in RT-PCR reactions with primers corresponding to specific sequences within hepP alone or within both genes (Fig. 2a). A reaction without template was included as a negative control (Fig. 2b). The expected 200-bp product was obtained with the primers for hepP alone (Fig. 2b). Additionally, we detected a 750-bp product using the primers that overlap both genes (Fig. 2b), indicating that $z b d P$-hepP are transcribed as an operon.

\section{Characterization of the putative heparinase encoded by hepP}

At this time, we decided to focus our efforts on hepP and its protein product HepP. Therefore, we obtained the 1650-bp fragment that contains the entire structural gene of hepP from PA14 by PCR. The gene was obtained minus the stop codon to allow synthesis of recombinant HepP (rHepP) with a 6xHis tag at the carboxy terminus. The fragment was cloned into the protein expression plasmid pBAD/Thio-TOPO, which carries the arabinose-inducible ara $\mathrm{BAD}$ promoter $\mathrm{P}_{\mathrm{BAD}}$, $\mathrm{HP}$-thioredoxin to maximize translation of the recombinant protein, and the $6 \mathrm{xHis}$ tag for purification of the protein plus the V5 epitope for recognition of the fusion protein. The resulting plasmid, pND1, was transformed into the $E$. coli expression host TOP10. Preliminary expression experiments determined that $0.02 \%$ arabinose produced optimal synthesis of $\mathrm{rHepP}$ (data not shown). TOP10/pND1was then grown in $50 \mathrm{~mL}$ of LB broth, induced with $0.02 \%$ arabinose, and cells were harvested $4 \mathrm{~h}$ post induction and processed as described in Methods. The rHepP was purified using nickel affinity column chromatography. Purification of rHepP was established by SDS-PAGE (Fig. 3a), and confirmed by Western blot analysis using anti-V5 antibody (Invitrogen) to detect the carboxy terminus V5 epitope within rHepP (Fig. 3b). 


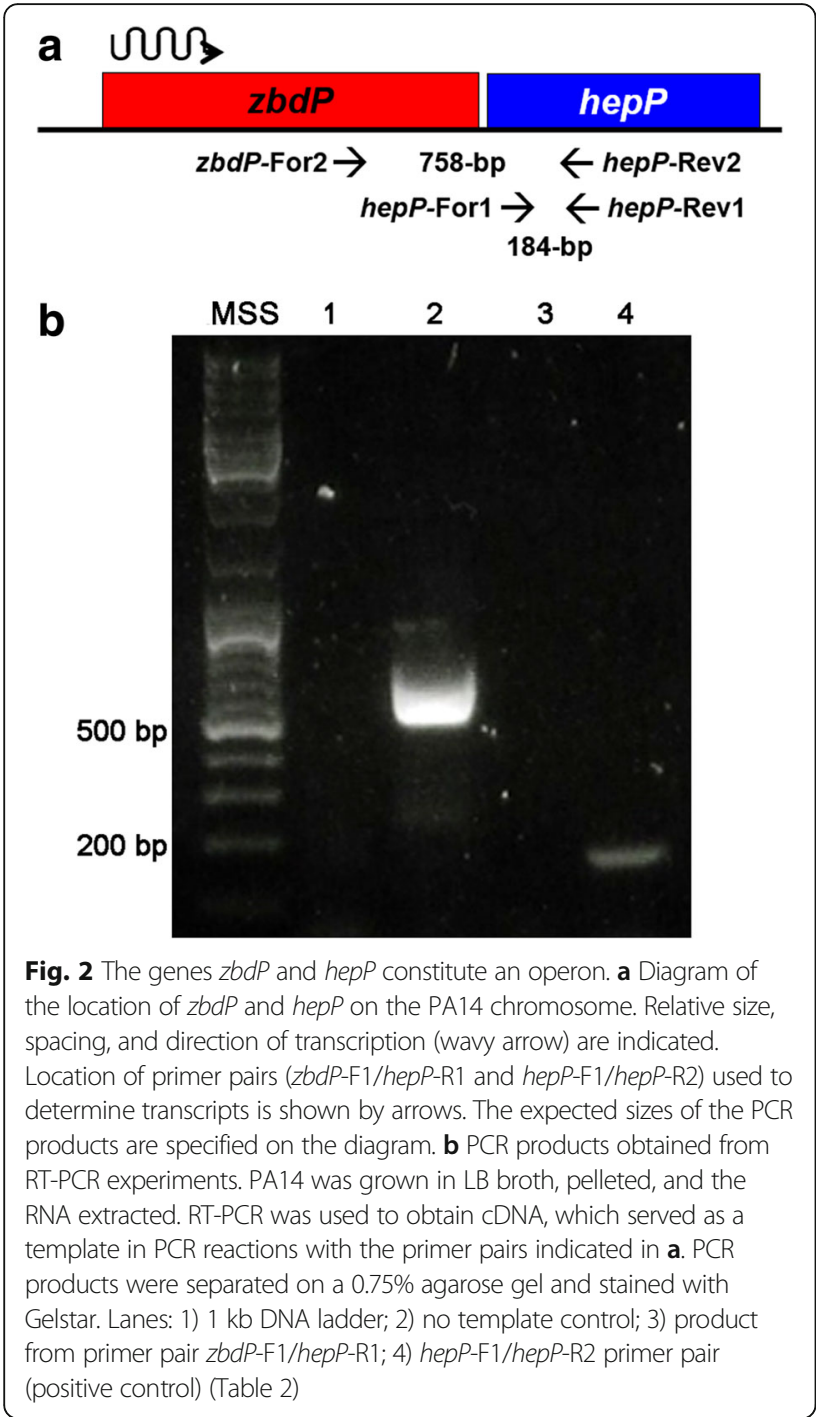

Once the successful purification of rHepP was confirmed, the next step was to examine its activity. To determine if the protein exhibits heparinase activity, we used the previously described heparinase plate assay [36]. An aliquot containing $28 \mu \mathrm{g}$ of rHepP in $20 \mu \mathrm{L}$ of protein elution buffer were spotted on the surface of the heparinagarose plates along with the buffer as a negative control and heparinase III from $P$. heparinus as a positive control. Following incubation for $1 \mathrm{~h}$ at $37{ }^{\circ} \mathrm{C}$, the plates were flooded with protamine sulfate, which reacts with intact heparin to form a white precipitate, and observed for clear zones indicative of heparinase activity. We detected clear zones with $P$. heparinus heparinase and with rHepP (Fig. 3c). These results suggest that PA14_23430 or hepP does encode a heparinase enzyme.

\section{Examination of PA14 mutants defective in hepP or $z b d P$} To examine the role of HepP in the virulence of PA14, we utilized PA14 mutant strains defective in the hepP and $z b d P$

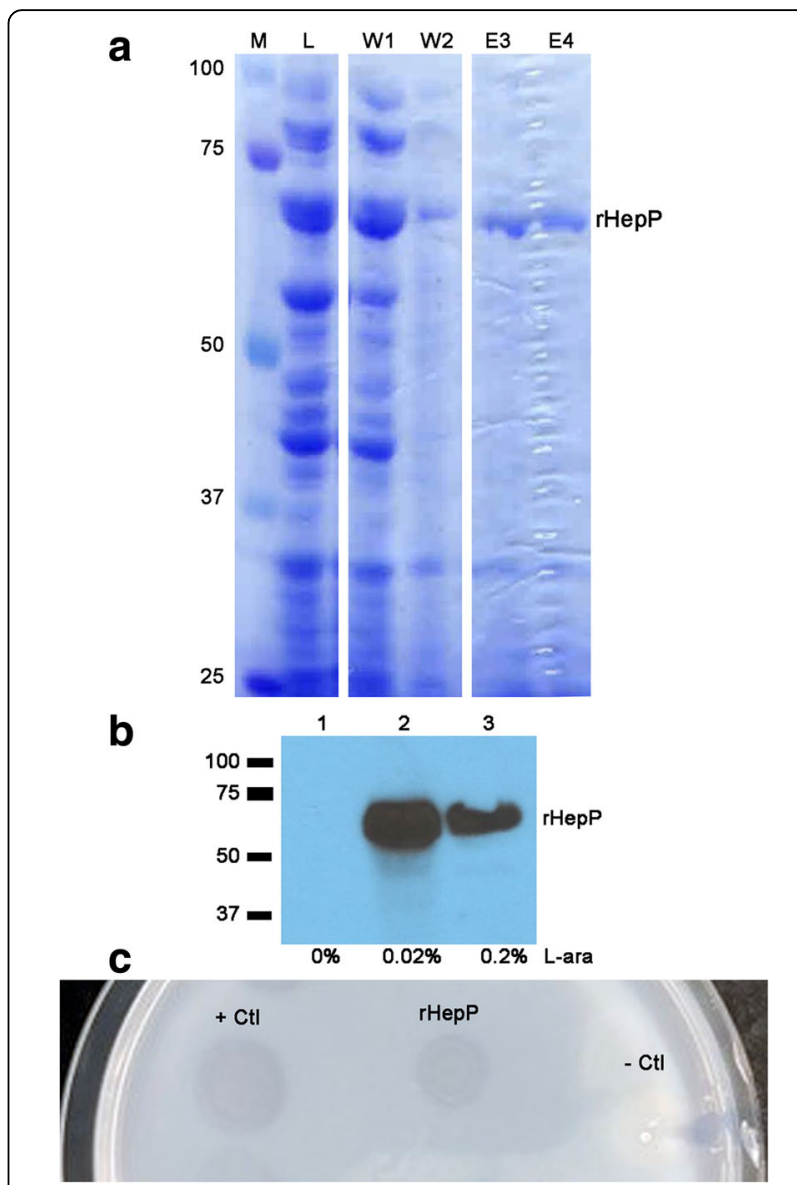

Fig. 3 Purification and functional characterization of HepP. a Expression and purification of recombinant HepP (rHepP) in E. coli. Plasmid pND1 containing the hepP structural gene was expressed from the arabinoseinducible promoter pBAD. Induction experiments were conducted using 0.02\% L-arabinose as described in Methods using the E. coli TOP10 strain as expression host. Proteins were purified by nickel column chromatography under native conditions, separated by $10 \%$ SDS PAGE and stained with Coomassie blue. Image is a compilation of lanes from the same gel. Lanes: $\mathrm{M}$, molecular weight standard in $\mathrm{kDa}$; L, whole cell lysate; W1 and W2, first and second of four column washes; E3 and E4, third and fourth of four elution fractions containing rHepP. $\mathbf{b}$ Immunoblotting to confirm rHepP purification. Equal amounts of purified proteins were separated by 10\% SDS-PAGE, transferred to nitrocellulose membrane, and probed with anti-V5 antibody (Invitrogen). The probed membranes were treated with anti-mouse horseradish peroxidase-conjugated $\lg \mathrm{G}$ and developed using ECL Western Blotting Substrate (Pierce). Proteins from cultures induced with $0,0.02$, and $0.2 \%$ L-arabinose (L-ara) are shown (lanes 1-3). The rHepP bands are indicated; the molecular weight standards are indicated in $\mathrm{kDa}$ by bars to the left of the blot. c rHepP exhibits heparinase activity. An agar plate containing $1 \mathrm{mg} / \mathrm{mL}$ porcine intestinal heparin in $1.5 \%$ agarose at $\mathrm{pH} 7$ was spotted with $28 \mu \mathrm{g}$ of $\mathrm{rHepP}$ in $20 \mu \mathrm{L}$ of protein elution buffer. As a positive control $(+\mathrm{Ctl}), 0.25 \mathrm{U}$ of heparinase III from P. heparinum was spotted on the agar; the protein buffer was used as a negative control $(-\mathrm{Ctl})$. After $1 \mathrm{~h}$ of incubation at $37^{\circ} \mathrm{C}, 2 \%$ protamine sulfate solution was poured on the entire plate. Following incubation at room temperature for $2 \mathrm{~h}$, the plate was examined for clear zones that indicate the presence of active heparinase 
genes. We obtained these mutants from the commerciallyavailable non-redundant whole genome scale PA14 mutant library (PA14NR Set) [30]. These two mutants carry the Mariner transposon MAR2xT7 [30] inserted within the structural genes; in PA14/MrT7::PA14_23430-480 (PA14Ahep $P$ ), the transposon is inserted at nucleotide (nt) 480; while PA14/MrT7::PA14_23420-118 (PA14 $\triangle z b d P$ ), the transposon insertion is at nt 118 . To verify the mutation in PA14 $\Delta$ hepP, we mapped the transposon insertion using PCR and restriction enzyme analyses. PCR analysis was conducted using primers matching sequences 94-bp upstream and 179-bp downstream of the hepP sequence ( $z b d P$-For3/hepP-Rev3, respectively) (Table 2, Additional file 1: Figure S3) and chromosomal DNA from PA14 and PA14 4 hepP as templates. We obtained the expected 1926-bp product from the chromosome of PA14 (the 1653-bp hepP gene plus the additional $273 \mathrm{nt}$ ) and the expected 2920-bp product, representing the addition of the 994-bp MAR2xT7 transposon, from the chromosome of PA14 4 hep (Fig. 4a). We confirmed the presence of $M A R 2 x T 7$ within PA14 $\triangle z b d P$ in a similar manner (data not shown).

Computer analysis revealed the presence of an EcoRV restriction enzyme site within MAR2xT7 and the lack of such a site within hepP (http://www.restrictionmapper.org/;
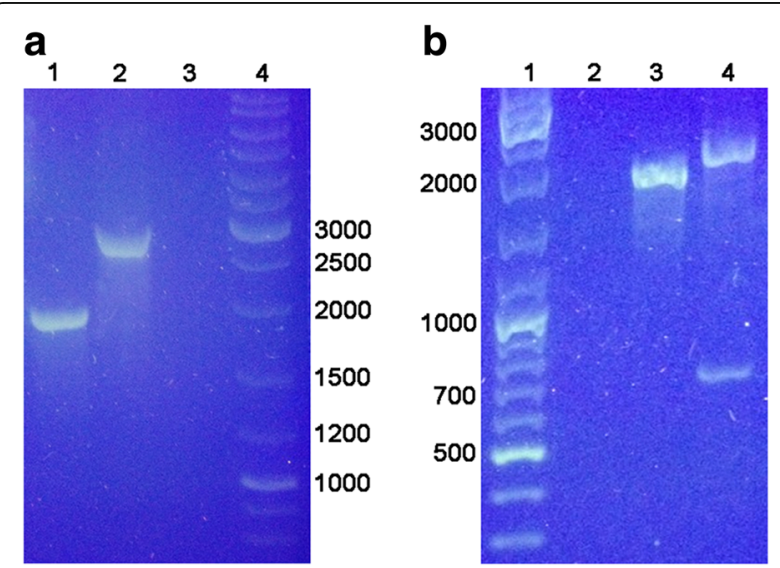

Fig. 4 Confirmation of the mutation in PA14 $\Delta$ hepP. PA14 and PA14 4 hepP were grown in $L B$ broth and the chromosomal DNA was extracted. a PCR analysis to detect the presence of MAR2XT7 within hepP. PCR reactions were run using the chromosomal DNA from each strain as a template and primers corresponding to the DNA sequences $94 \mathrm{bp}$ upstream and $179 \mathrm{bp}$ downstream of the hepP structural gene (zbdP-For3/hepP-Rev3, Table 2). The expected 1926-bp fragment from PA14 (lane 1) and the 2920-bp fragment (the additional $994 \mathrm{bp}$ from MAR2xT7) from PA14 hepP (lane 2) were detected. Lane 3 is a no-template control and the molecular size standards are in lane 4 . $\mathbf{b}$ Restriction analysis of the PCR products. The coding sequence for hepP does not contain an EcoRV restriction enzyme site, while MAR2XT7 contains a single ECoRV site. Digestion of the PCR products with ECORV failed to reduce the size of the 1926-bp fragment obtained from PA14 (lane 3) but resulted in the cleavage of the product obtained from PA14 $\Delta$ hepP into the expected $800 \mathrm{bp}$ and $2120 \mathrm{bp}$ fragments (lane 4). Lane 1 contains the molecular size standards; lane 2 was left empty accessed 12/12/2017). Therefore, to further confirm the mutation of hepP in PA14 4 hepP, we performed restriction enzyme digestion on the PCR products with EcoRV (New England Biolabs). As expected, there was no reduction in the size of the 1926-bp from PA14 after enzyme digestion (Fig. 4b). In contrast, digestion of the PCR product from PA14 $\triangle$ hepP produced two fragments of $800 \mathrm{bp}$ and $2120 \mathrm{bp}$ (Fig. 4b). The size of the two bands is consistent with the transposon insertion at 480 bp within hepP.

We then performed a growth curve analysis to determine if the presence of the transposon within either PA14 $\triangle$ hepP or PA14 $\Delta z b d P$ affected its growth. PA14, PA14 $\triangle h e p P$ and PA14 $\Delta z b d P$ were grown in LB broth for $48 \mathrm{~h}$ at $37{ }^{\circ} \mathrm{C}$. Samples were obtained every $4 \mathrm{~h}$ and serially diluted to determine the CFU/mL. The growth of the mutants paralleled that of their parent strain throughout the time frame of the analysis (Additional file 1: Figure S4).

\section{Loss of hepP or $z b d P$ affects pellicle and biofilm formation by PA14}

During static growth of PA14 and PA14 4 hepP or PA14 $\triangle z b d P$ in LB broth in $17 \mathrm{~mm} \times 100 \mathrm{~mm}$ polystyrene tubes, we observed a difference between the three strains in pellicle formation. When grown under static conditions, some bacteria, including $P$. aeruginosa migrate to the airliquid interface (ALI) and form biofilm-like structures [43]. These structures consist of bacterial cells and a pellicle, which is a matrix of extracellular polymer [45]. The ALI provides the bacteria with access to a high concentration of oxygen from the air and sufficient nutrients from the liquid. At $24 \mathrm{~h}$ of growth, PA14 and PA14 $\triangle z b d P$ formed a typical pellicle while PA14 $\triangle$ hepP did not (Fig. 5, red arrowheads). Additionally, there appeared to be more planktonic growth within the LB broth within the tube containing PA14 $\Delta h e p P$ compared to PA14 and PA14 $\triangle z b d P$ (Fig. 5, yellow arrowhead). At $48 \mathrm{~h}, \mathrm{PA} 14 \Delta h e p P$ appeared to form a thin pellicle, but there was still more growth within the tube compared to PA14 and PA14 $\Delta z b d P$ (Fig. 5).

Previous studies showed that $P$. aeruginosa flagella motility contributes to pellicle formation. $P$. aeruginosa flagellum-deficient mutants either produced pellicles of unusual structure or were delayed in pellicle formation $[43,45,55]$. To assess whether the delay in pellicle formation by PA14 $h e p P$ was due to a defect in flagellummediated motility, we compared all three strains using the swimming and twitching assays [42]. No difference in flagellar motility or pilus-related motility was detected (data not shown).

Since PA14 4 epP was defective in forming the biofilmlike pellicle structure at the ALI, it may also be defective in forming a biofilm on a solid surface. To examine this possibility, we compared the biofilms formed by PA14, PA14 $\triangle \mathrm{z} b d P$, and PA14 $\triangle h e p P$ using the ALI method of 


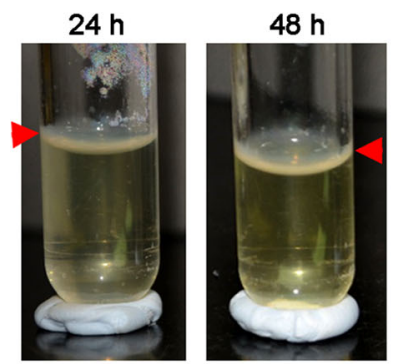

PA14

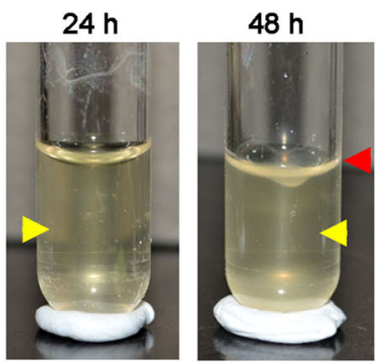

PA14 $h$ epP

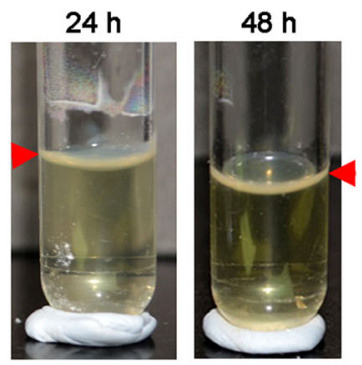

$\mathrm{PA} 14 \Delta \mathrm{zbdP}$

Fig. 5 Pellicle formation is delayed in PA14 hepP. Overnight growth of PA14, PA14 $\Delta$ hepP, and PA14 $\Delta z b d P$ was subcultured into fresh LB broth to a starting $\mathrm{OD}_{600}$ of 0.02 . Three- $\mathrm{mL}$ aliquots of the inoculum were dispensed into $17 \mathrm{~mm} \times 100 \mathrm{~mm}$ polystyrene tubes and the tubes were incubated under static conditions at $37^{\circ} \mathrm{C}$ for $24 \mathrm{~h}$ or $48 \mathrm{~h}$. Pellicles are visible at the air-liquid interface in the tubes containing PA14 and PA14 $\Delta z b d P$ at $24 \mathrm{~h}$ and with all three strains at $48 \mathrm{~h}$ (red arrowheads). Turbidity is present in the medium under the pellicles in the tubes containing PA14 $\mathrm{hepP}$ at 24 and $48 \mathrm{~h}$ (yellow arrowheads), while the turbidity clears from the medium in the tubes containing PA14 and PA14 $\Delta z b d P$ at $48 \mathrm{~h}$

biofilm development on the walls of polystyrene tubes [42], similar to the way in which we had observed the difference in pellicle formation. All strains were grown with gentle shaking in LB broth for 24 or $48 \mathrm{~h}$ and the amount of biofilm formed was measured using the crystal violet assay as described in Methods [37, 46]. As shown in Fig. 6, PA14 $\Delta$ hepP formed less biofilm than PA14 or PA14 $\triangle \mathrm{z} b d P$ at both 24 and $48 \mathrm{~h}$. Interestingly, the amount of biofilm formed by PA $14 \Delta \mathrm{z} b d P$ was significantly higher than that formed by PA14 at $24 \mathrm{~h}(P<0.05)$ and visibly higher (but not significantly higher) at $48 \mathrm{~h}$ (Fig. 6). These results suggest that the mutation in PA14 $\Delta$ hepP affected the ability of PA14 to form biofilms on solid surfaces as well as the pellicle at the ALI, while the mutation of PA14 $\triangle \mathrm{z} b d P$ enhanced the ability of PA14 to form biofilms on solid surfaces.

As the development of biofilms is controlled by quorum sensing (QS), we also examined the effect of the mutations in hepP or $z b d P$ on QS-controlled virulence factors of $P$. aeruginosa. We examined the production of pyocyanin, pyoverdine and elastase (LasB) by PA14 $\triangle h e p P$ or PA14 $\Delta z b d P$ using the assays previously described $[34,38,40,56]$. The level of each factor produced by the two mutants was comparable to that produced by PA14 (data not shown). We utilized RT-qPCR to examine the effect of the mutation on the expression of PA14 QS genes rhlA and lasI. We detected no difference in the expression of either gene (data not shown). Using the same approach, we ruled out any potential effect on the expression of the T3SS genes exoU and exs $D$. Again, the mutation of hepP did not alter the expression of either exoU or exs $D$ (data not shown).

\section{Loss of hepP reduces PA14 virulence while loss of $z b d P$ does not}

The above results showed that neither hepP nor $z b d P$ mutation affect the production or expression of several specific virulence factors. Therefore, rather than testing additional individual virulence factors, we decided to assess the effect of loss of either gene on the virulence of PA14 using the Caenorhabditis elegans pathogenesis model. This model, which has been used in numerous previous studies, involves the killing of the soil nematode $C$. elegans by $P$. aeruginosa [48, 57-59]. Tan et al. [48] previously demonstrated that, depending on the medium in which it is grown, PA14 produced either fast killing or slow killing of C. elegans. Fast killing, which occurs within a few hours, is partially mediated by bacterial secreted factors rather than live bacteria; it is produced when PA14 is grown on a high osmolarity medium. In contrast, slow killing, which occurs over the course of a few days and involves an infection process, is produced when PA14 is grown on a minimal medium (modified nematode growth media) [48].

We examined the slow killing process using $C$. elegans BW54, a temperature sensitive embryonic lethal mutant, fed on PA14, PA14 4 hepP, PA14 $\Delta z b d P$, or the E. coli strain OP50 (the common feeder host for maintenance of C. elegans) as a negative control. We monitored the killing/survival of BW54 fed on the different strains for $5 \mathrm{~d}$ post infection. The feeding of BW54 on a lawn of OP50 produced the least lethality (90\% survival) (Fig. 7). In contrast, on day 5 , the survival rate of BW54 that fed on a lawn of PA14 was $0 \%$ while the survival rate of worms fed on PA14 $\triangle$ zbdP was $20 \%$ (Fig. 7). However, BW54 that fed on a lawn of PA14 $\triangle$ hepP had a $70 \%$ survival rate on day 5 (Fig. 7). These results suggest that PA14 $\triangle$ hepP is defective in its in vivo virulence while PA $14 \Delta z b d P$ is still virulent.

We were puzzled by the phenotypic differences between PA14 $\Delta$ epP $P$ and PA14 $\Delta z b d P$. While PA14 $\Delta h e p P$ produced a significantly reduced biofilm, PA14 $\Delta z b d P$ formed a welldeveloped one (Fig. 6). Additionally, while PA14 $\Delta$ hepP caused only $30 \%$ lethality among C. elegans, PA14 $\Delta$ zbdP caused $80 \%$ lethality (Fig. 7). The Pseudomonas Genomic database indicated, and our PCR analysis confirmed, that $z b d P$ and $h e p P$ constitute an operon in which $z b d P$ is the first gene and the two genes are separated by eight bp (Fig. 2 and Additional file 1: Figure S3) [54]. Our PCR 


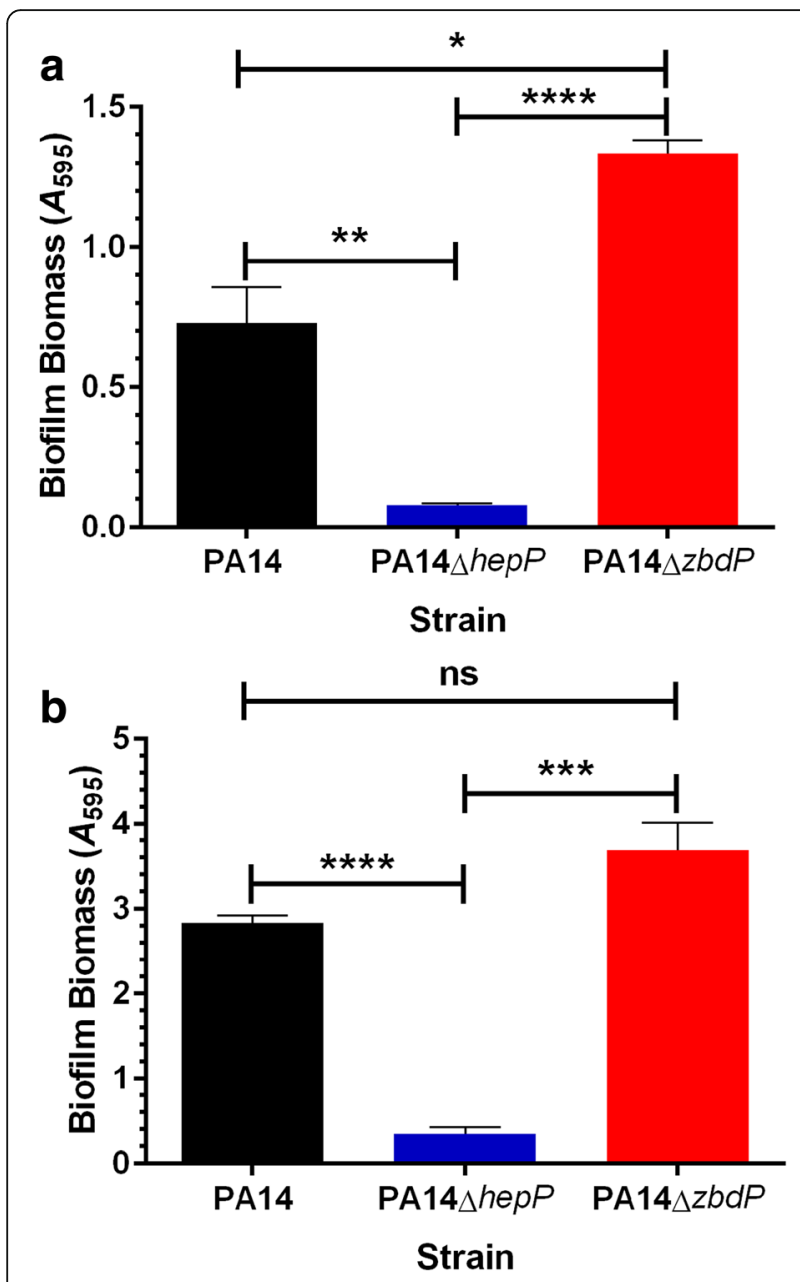

Fig. 6 Mutation of hepP significantly reduced biofilm formation. Overnight growth of PA14, PA14 $\triangle$ hepP, and PA14 $\Delta$ zbdP was subcultured into fresh $\mathrm{LB}$ broth to a starting $\mathrm{OD}_{600}$ of 0.02 . Three-mL aliquots of the inoculum were dispensed into $17 \mathrm{~mm} \times 100 \mathrm{~mm}$ polystyrene tubes and the tubes were incubated at $37^{\circ} \mathrm{C}$ with gentle shaking for $24 \mathrm{~h}$ (a) or $48 \mathrm{~h}$ (b). Following incubation, the tubes were thoroughly rinsed to remove loosely attached planktonic cells and the attached cells were stained with $1 \%$ crystal violet for $1 \mathrm{~h}$. The crystal violet was eluted with 95\% ethanol and the eluted crystal violet, representative of the biofilm biomass, was measured at $A_{595}$. Values represent means of 3 independent experiments \pm SEM; ${ }^{*}$, $P<0.05 ;{ }^{* *}, P<0.01 ;{ }^{* *}, P<0.001 ;{ }^{* * *}, P<0.0001 ; \mathrm{ns}$, no significant difference

analysis confirmed the presence of the operon (Fig. 2b). Therefore, we conducted RT-PCR experiments to determine if hepP is transcribed in PA14 $\triangle \mathrm{z} b d P$. RNA obtained from PA14 $\Delta z b d P$, and PA14 $\Delta$ hepP grown in LB broth was used reverse-transcribed and the cDNA used as templates in experiments using primer sets designed to detect internal fragments downstream of the transposon insertion in $z b d P$ ( $z b d P$-For1/zbdP-Rev1) or hepP (hepP-For2/hepPRev4) (Additional file 1: Figure S3). As expected, analysis of RNA from PA14 $\Delta z b d P$ showed no transcription of $z b d P$ (Fig. 8, lane 3). However, we did detect the 201-bp internal

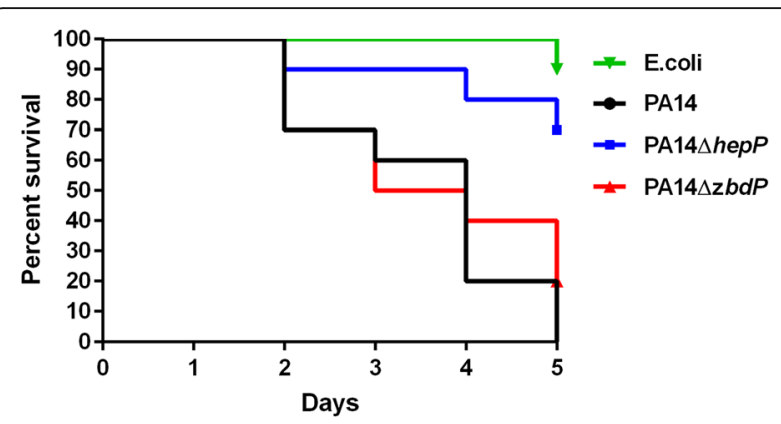

Fig. 7 Loss of hepP significantly enhanced the survival of C. elegans infected with PA14. Adult worms were infected with wild type PA14, PA14 1 hepP, or PA14 $\Delta z b d P$ and their survival was monitored daily for $5 \mathrm{~d}$. Worms fed on E. coli OP50 were used as the control. Values represent the totals of worms used in three independent experiments. Comparison of survival curves using the Log-rank (Mantel-Cox) test produced a $P$ value of $<0.0001$

hepP fragment from PA14 $\Delta z d P$ (Fig. 8, lane 2). Analysis of RNA from PA14 $\triangle$ hepP showed the presence of the 219bp internal $z b d P$ fragment (Fig. 8, lane 5), but we detected no transcript from the region of hepP below the transposon insertion (Fig. 8, lane 6). These results show that although $z b d P$-hepP form an operon, loss of $z b d P$ does not prevent transcription of hepP, which likely explains the observed phenotypic differences between the two mutants. A more detailed description of these experiments is provided in Additional file 1: Figure S5.

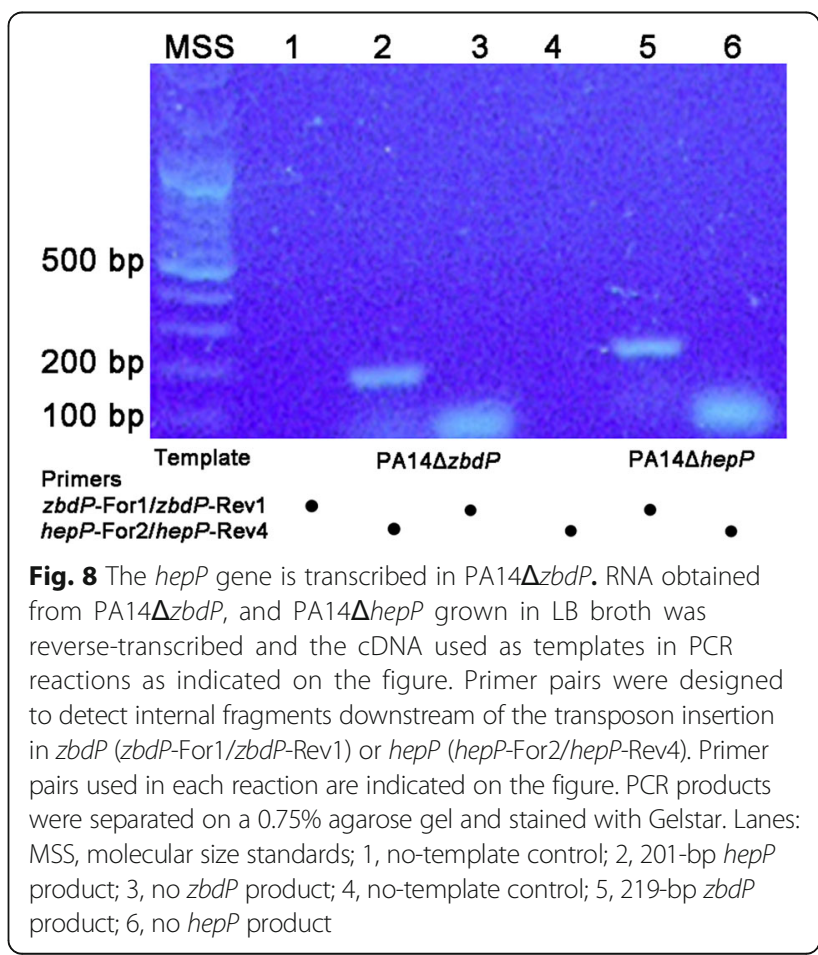




\section{Discussion}

Our results showed that, compared with its growth in LB broth, the growth of PA14 in whole blood from healthy volunteers (BHV) significantly enhanced the expression of PA14_23430, which encodes a putative heparinase (to be called hepP), and PA14_23420 that codes for a zinc-binding dehydrogenase (to be called $z b d P$ ) (Fig. 1). Moreover, compared with its growth in BHV, the growth of PA14 in whole blood from thermally injured patients (BTI) produced an additional increase in the expression of both genes (Fig. 1). These results suggest that these genes are related to the in vivo virulence of PA14. Previous studies have also shown that the growth of different pathogenic bacteria in blood enhanced the expression of numerous genes compared with growth in laboratory media $[3,15,60]$. For example, Graham et al. [60] showed that, compared with its growth in Todd Hewitt broth containing $0.2 \%$ yeast extract, the growth of $S$. pyogenes in blood increased the expression of $62.7 \%$ of transcripts including those of virulence factors such as $\operatorname{cov} R-\operatorname{cov} S$ (cov, control of virulence); while Kruczek et al. [15] showed that the growth of PA14 in BTI altered (enhanced or reduced) the expression of 2596 genes compared with its growth in BHV.

Interestingly, the hepP and $z b d P$ genes were also recovered in an earlier search for PA14 virulence-related genes done by a screening of the nonredundant PA14 transposon mutant library of 5850 clones that represent $75 \%$ of the total genome and $80 \%$ of the nonessential ORFs in this $P$. aeruginosa strain $[30,61]$. Using C. elegans infection models and a two-step screening process, Feinbaum et al. in 2012 [61] identified 399 mutants as potentially attenuated in their virulence in the primary screening in which the virulence was measured by the reduction of the C. elegans brood. Of these 399 genes, 180 were identified as potentially attenuated in virulence from the secondary screening based on the slow killing of $C$. elegans [61]. Both hepP and $z b d P$, referred to as ORF_11 and $O R F \_10$, respectively, were identified in the primary screening; however, $z b d P$ was not identified in the secondary screening suggesting that only hepP contributes moderately to the in vivo virulence of PA14 [61]. However, in 2006, Feinbaum and colleagues had identified both hepP and $z b d P$ as virulence-related genes in a different study [57]. Using the same C. elegans slow killing assay and the same transposon mutants described (which we call PA14 $\Delta h e p P$ and $(P A 14 \Delta z b d P)$, the results of our current study support the 2012 findings, but contradict the earlier report $[57,61]$. Additionally, our results suggest that hepP significantly contributes to PA14 virulence, rather than moderately [61], as feeding C. elegans PA14 $\Delta$ hepP increased the survival of the nematodes to $70 \%$ compared to the $0 \%$ survival rate among those fed PA14 (Fig. 7).

Very little homology was discovered for hepP or $z b d P$ at the DNA level, with only three strains of Pseudomonas aeruginosa (PA14OR, serotype 010, and H47921) carrying genes matching the hepP and $z b d P$ sequences. Similarly, PCR analysis of several different $P$. aeruginosa clinical isolates previously obtained from patients at University Medical Center or the Texas Tech Physicians clinics, Lubbock, TX did not detect either hepP or $z b d P$. However, interrogation of the nonredundant protein database (NCBI Protein BLAST; https://blast.ncbi.nlm.nih.gov/Blast.cgi; accessed 12/12/2017) revealed that proteins with $96-100 \%$ aa identity to HepP can be found in $38 P$. aeruginosa strains including PA14, BL04, BL16, BWH054, BWH058, BWHPSA043, BWHPSA044, CI127, HMSC057H01, and HMSC072F09; but are missing from the strains PAO1, PA103 and PAK as well as numerous other sequenced $P$. aeruginosa strains (data not shown). An additional search of the Pseudomonas Ortholog Groups (http://www.pseudomonas.com/orthologs/list?id=1654617; accessed 12/12/2017) found orthologous heparinases in conjunction with zinc-binding dehydrogenases in $P$. aeruginosa strains AZPAE15025 and PA14_CIA. Similarly, proteins 96$100 \%$ homologous to ZbdP were found in $31 \mathrm{P}$. aeruginosa including all of the strains named above except CI127. Dehydrogenase orthologs (not all were classified as zinc-binding proteins) were found in conjunction with heparinases in a number of different $P$. aeruginosa strains including 11 different AZPAE strains, WS136, Pae_CF67.11p, Pae_CF67.10q, PADK2_CF510, CF_PA39, H1I, BWHPSA008, BWHPSA010, and BHWPSA040 (data not shown).

Strains PAO1 and PA14 were originally isolated from infected wounds and both strains have been utilized extensively in in vitro and in vivo virulence studies. However, PA14 was shown to be more virulent than PAO1 in various infection models including the murine model of thermal injury and the nematode $C$. elegans, the plant Arabidopsis thaliana, and the wax moth Galleria mellonella infection models [31, 48, 62]. Using the C. elegans killing model, Lee et al. [57] also found PA14 to be one of the more virulent strains in their comparison of the in vivo virulence of $20 \mathrm{P}$. aeruginosa laboratory strains, environmental isolates and clinical isolates obtained from urine, blood, burn wounds, and respiratory secretions from cystic fibrosis (CF) patients. The CF lung isolate CF18 ranked first in virulence, PA14 ranked second, and PAO1 ranked eleventh [57]. While the PA14 and PAO1 genomes are remarkably similar, the PA14 chromosome is larger than that of PAO1 (6.5 Mb vs 6.3 Mb) [57]. Many of the PA14 genes that do not exist in PAO1 contribute to the pathogenicity of PA14 and are located within two pathogenicity islands, PAP-1 and PAP-2 $[57,63]$. PAP-1 is absent from the reference strain of PAO1 and only a portion of PAP-2 is present [63]. Neither hepP nor $z b d P$ is found within PAP-1 or PAP-2; instead they are found within a cluster of genes named PA14R38, which is present in PA14 [57]. PA14R38 was found in all 20 strains analyzed by Lee et al. [57], although the sequence of this gene cluster is so 
divergent that hepP and $z b d P$ are not present in PA14R38 or any of the other 19 strains. These results suggest that $h e p P$ and $z b d P$ genes are unique to PA14 and a number of other $P$. aeruginosa strains and were not horizontally transferred directly to them from other bacteria. However, similar heparinases can be found in the company of similar dehydrogenases in other Pseudomonas species, such as $P$. fluorescens F113, where the genes are in the same order and the proteins share a high level of homology (66\% identity and 78\% positive with no gaps for HepP; 74\% identity, $85 \%$ positives with no gaps for ZbdP). The strains $P$. bauzanensis W13Z2, P. chloritidismutans AW-1, P. chloroaphis HT66, P. denitrificans 148-PDEN, P. fluorescens AU6026, AU6308, and PA4C2, Pseudomonas sp. PAMC 26793, and P. stutzeri TS44 also carry sequences encoding proteins homologous to HepP and ZbdP. These findings suggest the functions of these two proteins are conserved among many different Pseudomonas species.

The microorganism from which heparinase was fully characterized is the nonpathogenic soil microorganism $P$. heparinus, which produces three heparinases: heparinase I, which acts on heparin; heparinase II, which acts on both heparin and heparan sulfate; and heparinase III, which acts on heparan sulfate only [27]. All three $P$. heparinus heparinases are commercially available and have been used extensively in studying wound healing mechanisms such as angiogenesis [27, 64-66]. The $42.5-\mathrm{kDa}$ heparinase I belongs to the alginate_lyase_2 superfamily, while the $84-\mathrm{kDa}$ heparinase II belongs to the heparinase_II_III superfamily, and the $70-\mathrm{kDa}$ heparinase III belongs to the alginate lyase and heparinase_II_III superfamilies.

Based on computer analysis the $61.8-\mathrm{kDa}$ HepP heparinase is similar to $P$. heparinus heparinase III in that it belongs to both the alginate lyase and heparinase_II_III superfamilies. Testing of purified recombinant PA14 HepP indicated that the protein is a functional heparinase (Fig. 3c) that cleaves heparin sodium salt, which suggests that HepP functions more similarly to $P$. heparinus heparinase I or heparinase II. Whether HepP can cleave heparan sulfate is not known at this time. While the heparinase II/III domain was found within other pathogenic bacteria including Shigella boydii, Vibrio parahemolyticus, V. vulnificus, and E. coli (Additional file 1: Figure S1b), neither the genes nor their products have been characterized in any of these pathogens. Heparinase has been purified from the soil bacterium Bacillus circulans [67]. Although rarely found in humans, there have been a few reports of this organism causing wound infections and fatal sepsis in immunocompromised patients [68]. Despite limited aa sequence homology between B. circulans heparinase and $P$. heparinus heparinases, $B$. circulans heparinase degrades both heparin and heparan sulfate similar to heparinase II [69]. Unlike with $P$. aeruginosa, the virulence factors and pathogenesis of $B$. circulans have not been characterized. Regardless of its exact nature as a heparinase (I, II, or III), HepP contributes to the virulence of $P$. aeruginosa as shown by the significant decrease in mortality of C. elegans fed PA (Fig. 7). To our knowledge, this is the first characterized virulence-related heparinase in a bacterial pathogen.

Based on the presence of the alginate lyase domain in HepP, the protein may play a role in the cleavage of proteoglycans within the human host. Proteoglycans are composed of core proteins to which chains of anionic polysaccharides and glycosaminoglycans (GAGs) are attached. GAGs consist of repeated disaccharide units $[22,70]$. Depending on the composition of these units, GAGs are classified as heparin or heparan sulfate, dermatan sulfate, chondroitin sulfate, keratin sulfate and hyaluronic acid [16, 70]. Among these classes, heparan sulfate proteoglycans (HSPGs) are the most complex and most physiologically relevant. HSPGs play a critical role in cellular processes including cell adhesion, organization of extracellular matrix, cytoskeleton organization, differentiation and morphogenesis, and tissue repair and inflammation [16, 71]. HSPGs also serve as coreceptors for cytokines, chemokines, and growth factors, a role that is associated with signal transduction; the binding of these ligands also protects them from proteolysis [71]. Shedding of the extracellular domain, leaving the membrane-spanning region with its intracellular domain intact, has been shown to play a key role in regulating the host response to tissue injury and inflammation [16, 18, 71, 72].

Many pathogenic bacteria utilize heparan sulfate for initial colonization and adherence [73]. Other pathogens, including Enterococcus faecalis and Listeria monocytogenes, utilize this mechanism for invasion and internalization [74]. The heparin-binding hemagglutinin of Mycobacterium tuberculosis not only facilitates adherence to epithelial cells but is also important in extrapulmonary dissemination of the infection $[16,75,76]$. P. aeruginosa induces shedding of the HSPG syndecan, which appears to augment its invasion of host cells $[77,78]$. The shed syndecan binds proline- and arginine-rich antimicrobial peptides leading to a reduced host defense and enhanced bacterial survival and pathogenesis [71]. Despite much evidence for the importance of heparan sulfate in bacterial pathogenesis, with the exception of our current study, no previous studies have connected heparinase with bacterial virulence. One earlier study investigating the production of heparinase by Bacteroides concluded that heparinase produced by anaerobes is not likely to contribute to the regional thrombophlebitis that occurs during anaerobic infections [79].

Both heparan sulfate and dermatan sulfate exist in the region of the terminal web and brush border of C. elegans intestine [80, 81]. Furthermore, mutations in C. elegans genes coding for heparin, heparan sulfate, HSPG core proteins, and their biosynthetic enzymes produced several 
phenotypic abnormalities including defects in cytokinesis and vulval morphogenesis, developmental abnormalities at embryonic stages, abnormal axon branching, defects in the formation and maintenance of the muscle mycofilament lattice, and embryonic lethality [82, 83]. Considering our current findings, heparinase may enhance PA14 virulence in C. elegans by disrupting numerous physiological processes and pathways that depend on HSPGs. Therefore, the observed significant reduction in the in vivo virulence of PA14 $\triangle$ hepP may be due to the failure of the strain to interfere with or disrupt one or more of these vital processes.

Another role for hepP in the virulence of PA14 is its contribution to pellicle formation at the air-liquid interface (ALI) and biofilm formation on a solid surface. With respect to pellicle formation, our results showed that when grown in a polystyrene tube under static conditions, thick pellicles are formed at the ALI by PA14 at $24 \mathrm{~h}$ post inoculation, but pellicle formation was delayed in PA14 $\Delta$ hepP until $48 \mathrm{~h}$, at which time a thinner pellicle became visible (Fig. 5). Previous studies showed that flagellum-mediated motility is required for pellicle formation in $P$. aeruginosa strain PAO1 [42]. A recent comparison of pellicle formation by PA14, a PA14 flagellum mutant (PA14 $\Delta f l g k)$ and a PA14 pilus mutant (PA14 $\triangle$ pilB) also showed that loss of flagellum-mediated motility, but not pilus-mediated motility, resulted in delayed pellicle formation [84]. We ruled out the possibility that hepP influences flagellar- or pilusrelated motility using swimming and twitching motility assays in which PA14 $h$ hepP was equal to PA14 in its motility (data not shown). Similar to the observations of Holscher et al. [84], the medium under the pellicle formed by PA14 $\triangle$ hepP remained turbid compared to PA14 (Fig. 5). The Pel exopolysaccharide is required for the formation of pellicles at the ALI [85]. Using RT-qPCR we investigated the possibility that hepP influences pellicle formation through pelC or pelE (Additional file 1: Table S1). However, amount of pelC and pelE transcripts produced by PA14 hepP was comparable to that produced by PA14 (data not shown).

With respect to biofilm development on a solid surface, PA14 4 epP failed to form a robust biofilm at $24 \mathrm{~h}$ post inoculation compared with PA14 (Fig. 6). Besides ruling out any effect of hepP on PA14 motility and pel transcription, both critical factors in biofilm initiation, we have also examined the possible effect of hepP on other potential contributors to biofilm development including the QS system. Assays for factors controlled by QS, such as LasB, pyocyanin, and pyoverdine, and the transcription of the QS genes rhlA and lasI produced the same results with PA14AhepP and PA14 (data not shown). Whether hepP affects the production of other biofilm-related factors is yet to be determined.
The genes $z b d P$ and hepP constitute an operon (Fig. 2) whose expression in PA14 is enhanced by thermal injury-induced changes in blood (Fig. 1 and Table 3). However, it is clear that despite transposon insertion in $z b d P$, hepP is still transcribed in PA14 $\Delta b d P$ (Fig. 8). Additionally, PA14 mutants defective in these genes showed phenotypic differences, with both biofilm production and lethality in the C. elegans model of slow killing reduced in PA14 $\Delta$ hepP but not in PA14 $\Delta z b d P$ (Figs. 6 and 7). These results suggest that hepP is reinitiated from a region within $z b d P$ below the transposon insertion. We are currently conducting experiments designed to identify the role of the potential zincbinding protein encoded by $z b d P$ and its relationship to the heparinase HepP.

Our work is significant because, to our knowledge, this is the first time a heparinase or heparin- and heparan sulfate-degrading enzyme has been characterized from $P$. aeruginosa. Such enzymes have been shown to have value as heparin antagonists and antineoplastic agents because of their ability to reduce neoangiogenesis [16] and heparinases I, II, and III to reduce neovascularization during tumor progression through their ability to alter the action of fibroblast growth factor [16, 20, 21, 27, 29]. In the future, heparinases may gain therapeutic value as targets for antimicrobials. We are currently conducting experiments to elucidate the effect of the HepP heparinase on PA14 virulence in a murine model.

\section{Conclusions}

Changes within the blood of severely burned patients significantly induced expression of hepP in PA14. The gene codes for an active heparinase enzyme, HepP, which influences PA14 in vivo virulence. To our knowledge this is the first time a heparinase, or heparin and heparin sulfate degrading enzyme, has been characterized from $P$. aeruginosa. HepP influences pellicle formation as well as biofilm development by PA14 and the protein is required for full virulence in the C. elegans model of slow killing.

\section{Additional file}

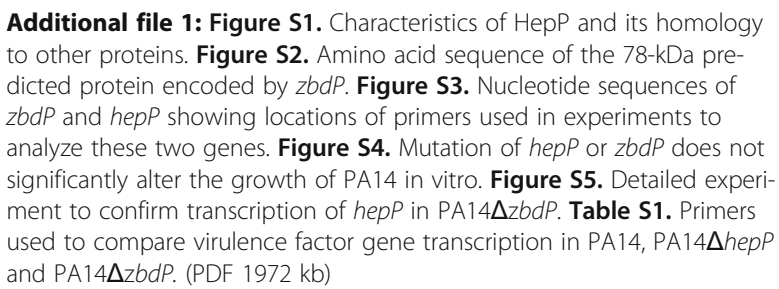

\section{Abbreviations}

aa: Amino acid; ALI: Air-liquid interface; BHV: Whole blood from healthy volunteers; BTI: Whole blood from severely burned (thermally-injured) patients; Cb: Carbenicillin; CFU: Colony forming units;

GAGs: Glycosaminoglycans; Gm: Gentamicin; HSGAGs: Heparin and heparan 
sulfate glycosaminoglycans; HSPGs: Heparin sulfate proteoglycans; LB: LuriaBertani; nt: Nucleotide; qPCR: Real time quantitative PCR; QS: Quorum sensing; RT-PCR: Reverse transcriptase PCR; Str: Streptomycin; T3SS: Type three secretion system; TSB-DC: Chelexed trypticase soy broth dialysate

\section{Acknowledgements}

The authors thank Dr. Cassandra Kruczek for her expert assistance with the RNA analyses, Dr. K. Rumbaugh for her kind gift of E. coli strain OP50 and Joanna E. Swickard for critical reading of this manuscript.

\section{Funding}

This study was supported by the Department of Surgery, Texas Tech University Health Sciences Center, Lubbock, TX.

\section{Availability of data and materials}

The data that support the findings of this study are available from the corresponding author upon reasonable request.

\section{Authors' contributions}

ND conducted all the experiments and wrote the manuscript. ANH coordinated the study, designed portions of the experiments and participated in the initial draft and the revision of the manuscript. JACH critically analyzed the data and revised the manuscript. JAG participated in the design of several experiments and provided critical clinical evaluation of the data. All authors read and approved the final manuscript.

\section{Ethics approval and consent to participate}

Human samples used in this study were previously obtained in a study approved by the Texas Tech University Health Sciences Center Institutional Review Board (Kruczek et al., 2016; reference 11).

\section{Consent for publication}

Not applicable.

\section{Competing interests}

The authors declare that they have no competing interests.

\section{Publisher's Note}

Springer Nature remains neutral with regard to jurisdictional claims in published maps and institutional affiliations.

\section{Author details}

'Department of Immunology and Molecular Microbiology, Texas Tech University Health Sciences Center, 3601 4th St. Mail Stop 6591, Lubbock, TX 79430, USA. ${ }^{2}$ Department of Medical Education, Texas Tech University Health Sciences Center, Lubbock, TX, USA. ${ }^{3}$ Department of Surgery, Texas Tech University Health Sciences Center, Lubbock, TX, USA.

Received: 11 July 2017 Accepted: 5 December 2017

\section{Published online: 16 December 2017}

\section{References}

1. Doring G, Pier GB. Vaccines and immunotherapy against Pseudomonas aeruginosa. Vaccine. 2008;26(8):1011-24.

2. Pier GB, Ramphal R. Pseudomonas aeruginosa. In: Mandell GL, Bennett JE, Dolin R, editors. Mandell, Douglas, and Bennett's principles and practice of infectious diseases, vol. 2. 7th ed. Philadelphia: Churchill Livingstone; 2010. p. 2835-60.

3. Colmer-Hamood JA, Dzvova N, Kruczek C, Hamood AN. In vitro analysis of Pseudomonas aeruginosa virulence using conditions that mimic the environment at specific infection sites. Prog Mol Biol Transl Sci. 2016;142:151-91.

4. Sadikot RT, Blackwell TS, Christman JW, Prince AS. Pathogen-host interactions in Pseudomonas aeruginosa pneumonia. Am J Respir Crit Care Med. 2005:171(11):1209-23.

5. Winstanley C, O'Brien S, Brockhurst MA. Pseudomonas aeruginosa evolutionary adaptation and diversification in cystic fibrosis chronic lung infections. Trends Microbiol. 2016;24(5):327-37.

6. Gellatly SL, Hancock RE. Pseudomonas aeruginosa: new insights into pathogenesis and host defenses. Pathog Dis. 2013;67(3):159-73.
7. van Delden C. Virulence factors in Pseudomonas aeruginosa. In: Ramos J-L, editor. Pseudomonas: virulence and gene regulation, vol. 2. New York: Kluwer Academic/Plenum Publishers; 2004. p. 3-45.

8. Church D, Elsayed S, Reid O, Winston B, Lindsay R: Burn wound infections. Clin Microbiol Rev 2006;19(2):403-434.

9. Griswold JA. White blood cell response to burn injury. Semin Nephrol. 1993;13(4):409-15.

10. Lederer JA, Rodrick ML, Mannick JA. The effects of injury on the adaptive immune response. Shock. 1999;11(3):153-9.

11. Rafla K, Tredget EE. Infection control in the burn unit. Burns. 2011;37(1):5-15.

12. Azzopardi EA, Azzopardi E, Camilleri L, Villapalos J, Boyce DE, Dziewulski P, Dickson WA, Whitaker IS. Gram negative wound infection in hospitalised adult burn patients-systematic review and metanalysis. PLoS One. 2014;9(4):e95042.

13. Branski LK, Al-Mousawi A, Rivero H, Jeschke MG, Sanford AP, Herndon DN. Emerging infections in burns. Surg Infect. 2009;10(5):389-97.

14. Streeter K, Katouli M. Pseudomonas aeruginosa: a review of their pathogenesis and prevalence in clinical settings and the environment. Infect Epidemiol Med. 2016;2(1):25-32.

15. Kruczek C, Kottapalli KR, Dissanaike S, Dzvova N, Griswold JA, ColmerHamood JA, Hamood AN. Major transcriptome changes accompany the growth of Pseudomonas aeruginosa in blood from patients with severe thermal injuries. PLoS One. 2016;11(3):e0149229.

16. Tripathi CK, Banga J, Mishra V. Microbial heparin/heparan sulphate lyases: potential and applications. Appl Microbial Biotechnol. 2012;94(2):307-21.

17. Shaya D, Tocilj A, Li Y, Myette J, Venkataraman G, Sasisekharan R, Cygler M. Crystal structure of heparinase II from Pedobacter heparinus and its complex with a disaccharide product. J Biol Chem. 2006;281(22):15525-35.

18. Bohlmann L, Chang CW, Beacham I, von Itzstein M. Exploring bacterial heparinase \|l activities with defined substrates. Chembiochem. 2015:16(8):1205-11.

19. Nakajima M, Irimura T, Nicolson GL. Tumor metastasis-associated heparanase (heparan sulfate endoglycosidase) activity in human melanoma cells. Cancer Lett. 1986;31(3):277-83.

20. Vlodavsky I, Eldor A, Haimovitz-Friedman A, Matzner Y, Ishai-Michaeli R, Lider O, Naparstek Y, Cohen IR, Fuks Z. Expression of heparanase by platelets and circulating cells of the immune system: possible involvement in diapedesis and extravasation. Invasion Metastasis. 1992;12(2):112-27.

21. Vlodavsky I, Friedmann Y. Molecular properties and involvement of heparanase in cancer metastasis and angiogenesis. J Clin Invest. 2001;108(3):341-7.

22. Gu Y, Lu M, Wang $Z$, Wu X, Chen Y. Expanding the catalytic promiscuity of heparinase III from Pedobacter heparinus. Chemistry. 2017;23(11):2548-51.

23. Parish CR, Freeman C, Hulett MD. Heparanase: a key enzyme involved in cell invasion. Biochim Biophys Acta. 2001;1471(3):M99-M108.

24. Godavarti R, Davis M, Venkataraman G, Cooney C, Langer R, Sasisekharan R. Heparinase III from Flavobacterium heparinum: cloning and recombinant expression in Escherichia coli. Biochem Biophys Res Commum. 1996;225(3):751-8.

25. Linker A, Hovingh P. The enzymatic degradation of heparin and heparitin sulfate I. The fractionation of a crude heparinase from flavobacteria. J Biol Chem. 1965:240(10):3724-8.

26. Sasisekharan R, Bulmer M, Moremen KW, Cooney CL, Langer R. Cloning and expression of heparinase I gene from Flavobacterium heparinum. Proc Natl Acad Sci U S A. 1993;90(8):3660-4.

27. Sasisekharan R, Moses MA, Nugent MA, Cooney CL, Langer R. Heparinase inhibits neovascularization. Proc Natl Acad Sci U S A. 1994;91(4):1524-8.

28. Su H, Blain F, Musil RA, Zimmermann JJ, Gu K, Bennett DC. Isolation and expression in Escherichia coli of hepB and hepC, genes coding for the glycosaminoglycan-degrading enzymes heparinase II and heparinase III, respectively, from Flavobacterium heparinum. Appl Environ Microbiol. 1996;62(8):2723-34.

29. Shenoy S, Harris RB, Sobel M. Development of heparin antagonists with focused biological activity. Curr Pharm Des. 1999;5(12):965-86.

30. Liberati NT, Urbach JM, Miyata S, Lee DG, Drenkard E, Wu G, Villanueva J, Wei T, Ausubel FM. An ordered, nonredundant library of Pseudomonas aeruginosa strain PA14 transposon insertion mutants. Proc Natl Acad Sci U S A. 2006;103(8):2833-8.

31. Rahme LG, Stevens EJ, Wolfort SF, Shao J, Tompkins RG, Ausubel FM. Common virulence factors for bacterial pathogenicity in plants and animals. Science. 1995:268(5219):1899-902.

32. Yahr TL, Mende-Mueller LM, Friese MB, Frank DW. Identification of type III secreted products of the Pseudomonas aeruginosa exoenzyme $S$ regulon. J Bacteriol. 1997;179(22):7165-8. 
33. Bradford MM. A rapid and sensitive method for the quantitation of microgram quantities of protein utilizing the principle of protein-dye binding. Anal Biochem. 1976;72:248-54.

34. Hamood AN, Griswold J, Colmer J. Characterization of elastase-deficient clinical isolates of Pseudomonas aeruginosa. Infect Immun. 1996;64(8):3154-60.

35. Laemmli UK. Cleavage of structural proteins during the assembly of the head of bacteriophage T4. Nature. 1970;227(5259):680-5.

36. Zimmermann JJ, Langer R, Cooney CL. Specific plate assay for bacterial heparinase. Appl Environ Microbiol. 1990;56(11):3593-4.

37. Schaber JA, Carty NL, McDonald NA, Graham ED, Cheluvappa R, Griswold JA, Hamood AN. Analysis of quorum sensing-deficient clinical isolates of Pseudomonas aeruginosa. J Med Microbiol. 2004;53(Pt 9):841-53.

38. Stintzi A, Johnson Z, Stonehouse M, Ochsner U, Meyer JM, Vasil ML, Poole K. The pvc gene cluster of Pseudomonas aeruginosa: role in synthesis of the pyoverdine chromophore and regulation by PtxR and PvdS. J Bacteriol. 1999;181(13):4118-24.

39. MacDonald JC. Biosynthesis of pyocyanine. Can J Microbiol. 1963;9(6):809-19.

40. Essar DW, Eberly L, Crawford IP. Evolutionary differences in chromosomal locations of four early genes of the tryptophan pathway in fluorescent pseudomonads: DNA sequences and characterization of Pseudomonas putida trpE and trpGDC. J Bacteriol. 1990;172(2):867-83.

41. Deziel E, Comeau Y, Villemur R. Initiation of biofilm formation by Pseudomonas aeruginosa 57RP correlates with emergence of hyperpiliated and highly adherent phenotypic variants deficient in swimming, swarming, and twitching motilities. J Bacteriol. 2001;183(4):1195-204.

42. OToole GA, Kolter R. Flagellar and twitching motility are necessary for Pseudomonas aeruginosa biofilm development. Mol Microbiol. 1998;30(2):295-304.

43. Friedman L, Kolter R. Genes involved in matrix formation in Pseudomonas aeruginosa PA14 biofilms. Mol Microbiol. 2004;51(3):675-90.

44. Kulasekara HD, Ventre I, Kulasekara BR, Lazdunski A, Filloux A, Lory SA. Novel two-component system controls the expression of Pseudomonas aeruginosa fimbrial cup genes. Mol Microbiol. 2005;55(2):368-80.

45. Li Z, Chen JH, Hao Y, Nair SK. Structures of the PelD cyclic diguanylate effector involved in pellicle formation in Pseudomonas aeruginosa PAO1. J Biol Chem. 2012;287(36):30191-3204.

46. O'Toole GA, Kolter R. Initiation of biofilm formation in Pseudomonas fluorescens WCS365 proceeds via multiple, convergent signalling pathways: a genetic analysis. Mol Microbiol. 1998;28(3):449-61.

47. Qaisar U, Luo L, Haley CL, Brady SF, Carty NL, Colmer-Hamood JA, Hamood AN. The pvc operon regulates the expression of the Pseudomonas aeruginosa fimbrial chaperone/usher pathway (cup) genes. PLoS One. 2013;8(4):e62735.

48. Tan MW, Mahajan-Miklos S, Ausubel FM. Killing of Caenorhabditis elegans by Pseudomonas aeruginosa used to model mammalian bacterial pathogenesis. Proc Natl Acad Sci U S A. 1999;96(2):715-20.

49. Brenner S. The genetics of Caenorhabditis elegans. Genetics. 1974;77(1):71-94.

50. Marchler-Bauer A, Bo Y, Han L, He J, Lanczycki CJ, Lu S, Chitsaz F, Derbyshire MK, Geer RC, Gonzales NR, et al. CDD/SPARCLE: functional classification of proteins via subfamily domain architectures. Nucleic Acids Res. 2017;45(D1):D200-3.

51. Altschul SF, Madden TL, Schaffer AA, Zhang J, Zhang Z, Miller W, Lipman DJ, Gapped BLAST. PSI-BLAST: a new generation of protein database search programs. Nucleic Acids Res. 1997;25(17):3389-402.

52. Kostakioti M, Newman CL, Thanassi DG, Stathopoulos C. Mechanisms of protein export across the bacterial outer membrane. J Bacteriol. 2005;187(13):4306-14.

53. Yu NY, Wagner JR, Laird MR, Melli G, Rey S, Lo R, Dao P, Sahinalp SC, Ester M, Foster $L$, et al. PSORTb 3.0: improved protein subcellular localization prediction with refined localization subcategories and predictive capabilities for all prokaryotes. Bioinformatics. 2010;26(13):1608-15.

54. Winsor GL, Griffiths EJ, Lo R, Dhillon BK, Shay JA, Brinkman FS. Enhanced annotations and features for comparing thousands of Pseudomonas genomes in the Pseudomonas genome database. Nucleic Acids Res. 2016;44(D1):D646-53.

55. Vasseur P, Vallet-Gely I, Soscia C, Genin S, Filloux A. The pel genes of the Pseudomonas aeruginosa PAK strain are involved at early and late stages of biofilm formation. Microbiology. 2005;151(Pt 3):985-97.

56. Schad PA, Bever RA, Nicas TI, Leduc F, Hanne LF, Iglewski BH. Cloning and characterization of elastase genes from Pseudomonas aeruginosa. J Bacteriol. 1987;169(6):2691-6.

57. Lee DG, Urbach JM, Wu G, Liberati NT, Feinbaum RL, Miyata S, Diggins LT, He J, Saucier M, Deziel E, et al. Genomic analysis reveals that Pseudomonas aeruginosa virulence is combinatorial. Genome Biol. 2006;7(10):R90.
58. Mahajan-Miklos S, Tan MW, Rahme LG, Ausubel FM. Molecular mechanisms of bacterial virulence elucidated using a Pseudomonas aeruginosaCaenorhabditis elegans pathogenesis model. Cell. 1999;96(1):47-56.

59. Tan MW, Rahme LG, Sternberg JA, Tompkins RG, Ausubel FM. Pseudomonas aeruginosa killing of Caenorhabditis elegans used to identify P. aeruginosa virulence factors. Proc Natl Acad Sci U S A. 1999;96(5):2408-13.

60. Graham MR, Virtaneva K, Porcella SF, Barry WT, Gowen BB, Johnson CR, Wright FA, Musser JM, Group A. Streptococcus transcriptome dynamics during growth in human blood reveals bacterial adaptive and survival strategies. Am J Pathol. 2005;166(2):455-65.

61. Feinbaum RL, Urbach JM, Liberati NT, Djonovic S, Adonizio A, Carvunis AR, Ausubel FM. Genome-wide identification of Pseudomonas aeruginosa virulence-related genes using a Caenorhabditis elegans infection model. PLoS Pathog. 2012;8(7):e1002813.

62. Choi JY, Sifri CD, Goumnerov BC, Rahme LG, Ausubel FM, Calderwood SB. Identification of virulence genes in a pathogenic strain of Pseudomonas aeruginosa by representational difference analysis. J Bacteriol. 2002;184(4):952-61.

63. He J, Baldini RL, Deziel E, Saucier M, Zhang Q, Liberati NT, Lee D, Urbach J, Goodman HM, Rahme LG. The broad host range pathogen Pseudomonas aeruginosa strain PA14 carries two pathogenicity islands harboring plant and animal virulence genes. Proc Natl Acad Sci U S A. 2004;101(8):2530-5.

64. Raman K, Kuberan B. Differential effects of heparitinase I and heparitinase III on endothelial tube formation in vitro. Biochem Biophys Res Commun. 2010;398(2):191-3.

65. Yousefimanesh H, Abdolahi F, Jahromi BM, Bagheri M, Noorafshan A, Zarifkar A Mirkhani H. Effect of intradermal injection of heparinase III on skin wound healing in diabetic rats. G Ital Dermatol Venereol. 2014;149(4):427-33.

66. Zarifkar A, Habibi H, Namazi MR, Hosseininasab SJ, Mosavat SH, Khatibi A, Habibi $\mathrm{H}$. Administration of heparanase-III improves the survival and angiogenesis of rat skin autografts. G Ital Dermatol Venereol. 2009;144(2):195-8.

67. Logan NA, Old DC, Dick HM. Isolation of Bacillus circulans from a wound infection. J Clin Pathol. 1985;38(7):838-9.

68. Alebouyeh M, Gooran OP, Azimi-rad M, Tajbakhsh M, Tajeddin E, Jahani Sherafat S, Nazemalhosseini Mojarad E, Zali M. Fatal sepsis by Bacillus circulans in an immunocompromised patient. Iran J Microbiol. 2011;3(3):156-8.

69. Yoshida E, Arakawa S, Matsunaga T, Toriumi S, Tokuyama S, Morikawa K, Tahara Y. Cloning, sequencing, and expression of the gene from Bacillus circulans that codes for a heparinase that degrades both heparin and heparan sulfate. Biosci Biotechnol Biochem. 2002;66(9):1873-9.

70. Esko JD, Kimata K, Lindahl U. Proteoglycans and sulfated glycosaminoglycans. In: Varki A, Cummings RD, Esko JD, et al., editors. Essentials of Glycobiology. 2nd ed. Cold Spring Harbor: Cold Spring Harbor Laboratory Press; 2009.

71. Bernfield M, Gotte M, Park PW, Reizes O, Fitzgerald ML, Lincecum J, Zako M. Functions of cell surface heparan sulfate proteoglycans. Annu Rev Biochem. 1999;68:729-77.

72. Nizet V, Ohtake T, Lauth X, Trowbridge J, Rudisill J, Dorschner RA, Pestonjamasp V, Piraino J, Huttner K, Gallo RL. Innate antimicrobial peptide protects the skin from invasive bacterial infection. Nature. 2001;414(6862):454-7.

73. Chen T, Swanson J, Wilson J, Belland RJ. Heparin protects Opa ${ }^{+}$Neisseria gonorrhoeae from the bactericidal action of normal human serum. Infect Immun. 1995;63(5):1790-5.

74. Alvarez-Domínguez C, Vazquez-Boland JA, Carrasco-Marin E, Lopez-Mato P, Leyva-Cobian F. Host cell heparan sulfate proteoglycans mediate attachment and entry of Listeria monocytogenes, and the listerial surface protein ActA is involved in heparan sulfate receptor recognition. Infect Immun. 1997;65(1):78-88.

75. Menozzi FD, Rouse JH, Alavi M, Laude-Sharp M, Muller J, Bischoff R, Brennan MJ, Locht C. Identification of a heparin-binding hemagglutinin present in mycobacteria. J Exp Med. 1996;184(3):993-1001.

76. Pethe K, Alonso S, Biet F, Delogu G, Brennan MJ, Locht C, Menozzi FD. The heparin-binding haemagglutinin of $M$. tuberculosis is required for extrapulmonary dissemination. Nature. 2001;412(6843):190-4.

77. Garcia B, Merayo-Lloves J, Martin C, Alcalde I, Quiros LM, Vazquez F. Surface proteoglycans as mediators in bacterial pathogens infections. Front Microbiol. 2016;7:220.

78. Manon-Jensen T, Itoh Y, Couchman JR. Proteoglycans in health and disease: the multiple roles of syndecan shedding. FEBS J. 2010;277(19):3876-89.

79. Riley TV. Heparinase production by anaerobic bacteria. J Clin Pathol. 1987;40(4):384-6.

80. MCGhee JD, Sleumer MC, Bilenky M, Wong K, McKay SJ, Goszczynski B, Tian $H$, Krich ND, Khattra J, Holt RA. The ELT-2 GATA-factor and the global 
regulation of transcription in the C. elegans intestine. Dev Biol. 2007;302(2):627-45.

81. Tarsitano M, De Falco S, Colonna V, McGhee JD, Persico MG. The C. elegans pvf-1 gene encodes a PDGFNEGF-like factor able to bind mammalian VEGF receptors and to induce angiogenesis. FASEB J. 2006;20(2):227-33.

82. Mizumoto S, Kitagawa H, Sugahara K. Biosynthesis of heparin and heparan sulfate. In: Garg HG, Linhardt RJ, Hales CA, editors. Chemistry and biology of heparin and Heparan sulfate, 1st ed. Oxford: Elsevier science; 2005. p. 203-43.

83. Sasisekharan R, Venkataraman G. Heparin and heparan sulfate: biosynthesis, structure and function. Curr Opin Chem Biol. 2000;4(6):626-31.

84. Holscher T, Bartels B, Lin YC, Gallegos-Monterrosa R, Price-Whelan A, Kolter R, Dietrich LE, Kovacs AT. Motility, chemotaxis and aerotaxis contribute to competitiveness during bacterial pellicle biofilm development. J Mol Biol. 2015;427(23):3695-708.

85. Bouffartigues E, Duchesne R, Bazire A, Simon M, Maillot O, Dufour A Feuilloley M, Orange N, Chevalier S. Sucrose favors Pseudomonas aeruginosa pellicle production through the extracytoplasmic function sigma factor SigX. FEMS Microbiol Lett. 2014;356(2):193-200.

Submit your next manuscript to BioMed Central and we will help you at every step:

- We accept pre-submission inquiries

- Our selector tool helps you to find the most relevant journal

- We provide round the clock customer support

- Convenient online submission

- Thorough peer review

- Inclusion in PubMed and all major indexing services

- Maximum visibility for your research

Submit your manuscript at www.biomedcentral.com/submit
Biomed Central 